\title{
Animal and Non-Animal Experiments in Nanotechnology - the Results of a Critical Liferature Survey
}

\author{
Ursula G. Sauer
}

Scientific Consultancy - Animal Welfare, Neubiberg/Munich, Germany

\begin{abstract}
Summary
A literature survey funded by the Foundation Animalfree Research was performed to obtain an overview on animal experiments in nanotechnology. Scientific articles from Germany, France, the United Kingdom, Italy, the Netherlands and Switzerland published between 2004 and 2007 were collected. A total of 164 articles was retrieved covering in vivo nanotechnological research. The majority of animal experiments were conducted in "nanomedicine", i.e. nanotechnology in the health care area, to study targeted drug, vaccine or gene delivery. Further areas of research relate to nanotechnology-based imaging technologies, the toxicity of nanomaterials, tissue engineering for regenerative treatments, and magnetic tumour thermotherapy. Many experiments were classified as moderately and even severely distressful to the animals. Due to the significance of the scientific topics pursued, the possible scientific benefit of the research depicted in the articles is also assigned to be moderate to high. Nevertheless, it has to be asked whether such animal experiments are truly the only means to answer the scientific questions addressed in nanotechnology. An overview on non-animal test methods used in nanotechnological research revealed a broad spectrum of methodologies applied in a broad spectrum of scientific areas, including those for which animal experiments are being performed. Explicit incentives to avoid animal experiments in nanotechnology currently can only be found in the area of nanotoxicology, but not in the area of nanomedicine. From the point of view of animal welfare, not least because of the new technologies that arise due to nanotechnology, it is time for a paradigm change both in fundamental and applied biomedical research to found research strategies on non-animal test methods.
\end{abstract}

Keywords: nanotechnology, nanomedicine, nanotoxicology, targeted drug delivery, severity classification, cost-benefit analysis

\section{Introduction}

\subsection{Animal welfare relevance of nanotechnology} "Nanotechnology is increasingly considered to be the future technology", the German Federal Ministry for Research declares on its website where it presents an overriding strategy to promote the new technology ${ }^{1}$. The European Commission has also recognized the economic and political importance of nanotechnologies, in 2004, in its Communication depicting the framework for a European strategy for nanotechnology (Commission of the European Communities, 2004), and one year later in spelling out an action plan on nanosciences $*^{2}$ and nanotechnologies (Commission of the European Communities,
2005). In its Communication from September 2007 on the first implementation phase of the action plan 2005-2009 on nanosciences and nanotechnology (Commission of the European Communities, 2007), the Commission confirms its full active support of nanosciences and nanotechnologies: "Nanotechnology provides important potential for boosting quality of life and industrial competitiveness in Europe. Its development and use should not be delayed, unbalanced or left to chance. The European Commission plays two important roles in the development of nanosciences and nanotechnologies: as policy maker and as funding body for research and innovation."

Received $25^{\text {th }}$ December 2008, received in revised form and accepted for publication $31^{\text {th }}$ March 2009

1 http://www.bmbf.de/en/nanotechnologie.php

2 Terms marked with an asterisk $\left(^{*}\right)$ are explained in the glossary at the end of the article. 


\section{Infobox 1 - Expectations and visions on nanotechnology}

Materials science developments using nanotechnology are far-reaching and are expected to impact upon virtually all sectors. Nanoparticles are already used for reinforcing materials or functionalising cosmetics. Surfaces can be modified using nanostructures to be, for example, scratch-proof, unwettable, clean or sterile. Selective grafting of organic molecules through surface nanostructuring is expected to impact upon the fabrication of biosensors and molecular electronics devices...

Commission of the European Communities (2004), Page 4

Nanotechnology is an area which has highly promising prospects for turning fundamental research into successful innovations. Not only to boost the competitiveness of our industry but also to create new products that will make positive changes in the lives of our citizens, be it in medicine, environment, electronics or any other field. Nanosciences and nanotechnologies open up new avenues of research and lead to new, useful, and sometimes unexpected applications. Novel materials and new engineered surfaces allow to make products that perform better. New medical treatments are emerging for fatal diseases, such as brain tumours and Alzheimer's disease.

Commission of the European Communities (2005), Page 1

Nanotechnology* involves investigations and technological developments on the scale of 1-100 nanometres, with one nanometre being one millionth of a millimetre ${ }^{3}$. Due to their small size, nanoscale particles exhibit novel physical characteristics compared to the same bulk chemical without nanoscale features. Substances and products with nanoscale* sizes or nanoscale surface structures are being developed and produced to be used in energy technology, in environmental and information technologies and also in the healthcare area.

The term "nanoscience" refers to the study of (biological) objects and structures on the nanoscale level. Nanotechnology in the healthcare area has been called "nanomedicine*" (European Technology Platform Nanomedicine, 2005). High expectations are laid into nanomedical research: "Nanoscience... can contribute towards addressing many of the problems facing today's society: medical applications, including e.g. miniaturised diagnostics that could be implanted for early diagnosis of illness. Nanotechnology-based coatings can improve the bioactivity and biocompatibility of implants. Self-organising scaffolds pave the way for new generations of tissue engineering and bio-mimetic materials, with the long-term potential of synthesising organ replacements. Novel systems for targeted drug delivery are under development and recently nanoparticles could be channelled into tumour cells in order to treat them e.g. through heating" (Commission of the European Communities, 2004, page 4).
These statements point to the importance assigned to nanotechnology by those responsible in politics and science, and also to two areas of possible use of laboratory animals in the area of nanotechnology: both for research in nanomedicine and for the safety testing of materials with nanoscale properties. As a result, a continuous increase in animal experiments in these areas over the coming years seems likely unless effective preventive measures are put in force.

\subsection{EU animal welfare legislation}

The Animal Welfare Protocol of Amsterdam amending the Treaty of the European Union (Treaty of Amsterdam) calls upon the Community and the Member States to "pay full regard to the welfare requirements of animals" when "formulating and implementing the Community's agriculture, transport, internal market and research policies".

Article 23(1) of Directive 86/609/EEC on the Protection of Laboratory Animals (Council Directive 86(609/EEC) requests the Commission and the Member States to encourage research "into the development and validation of alternative techniques which could provide the same level of information as that obtained in experiments using animals but which involve fewer animals or which entail less painful procedures". Article 7(2) of this Directive prohibits the performance of animal experiments if scientifically satisfactory non-animal methods are reasonably and practicably available.

Likewise, Article 20(1 and 2) of the Swiss Federal Act on Animal Protection lays down that pain, suffering or distress may only be inflicted upon an animal or it may only be put into anxiety, as far as this is indispensable for the purpose of the experiment. Experiments with animals of higher evolutionary stages may only performed if the purpose cannot be achieved with animals of lower evolutionary stages and no suitable alternative methods exist (Swiss Federal Government, 2005).

In consequence, the European Commission and its Member States, as well as other European countries, have a legal obligation to make allowance for animal welfare issues from the beginning when developing and pursuing new policies - such as those regarding nanosciences and nanotechnologies. They are called to actively promote the development of specific nonanimal test methods for relevant scientific purposes in order to counteract any resulting increase in animal use.

\subsection{Goal and contents of the literature survey}

It is against this background that it is the goal of the literature survey to reveal those scientific topics in the areas of nanomedicine and nanotechnology, in which laboratory animal use is most likely to occur and in which therefore the European Union, the EU Member States and also other European Countries should become active most urgently in order to fulfil their animal welfare obligations as spelled out in the Protocol of Amsterdam and in Directive 86/609/EEC and their respective national legislations.

In order to determine main areas of concern from the point of view of animal welfare (such as specific scientific topics with

\footnotetext{
3 To date, no official definition of the term "nanotechnology" exists.
} 
disproportionately high increase in animal use over the last couple of years or specific especially distressful animal experiments), the survey at hand provides a comprehensive overview of those scientific areas in which animals are already being used in fundamental biomedical research in nanomedicine and for the safety testing of nanotechnological products (Chapter 2).

To enable an in-depth discussion of such animal experiments and since the term "animal experiment" encompasses a broad variety of different procedures, Chapter 3 provides examples for concrete animal experiments performed in nanotechnology and the nanosciences. Chapter 4 discusses a classification of the severity of selected animal experiments performed in nanotechnology and nanosciences and aims to determine the scientific benefits of the results of these procedures in order to perform a harm-benefit analysis thereupon. Such a balancing of the harm inflicted upon the animals during a procedure against the benefit of the procedure not only serves to evaluate the indispensability of the experiments performed but also to determine those areas of animal use, in which the development of alternative methods in accordance with the principle of the $3 \mathrm{Rs}$ is most urgently needed.

To complement the overview on biomedical research in the realms of nanotechnology and nanosciences, Chapter 5 presents a brief overview on potential 3 Rs alternatives to the animal experiments revealed by the literature survey, thereby pointing to possible ways to prevent an increase in the numbers of animals used for scientific procedures to due research in the nanosciences or the application of nanotechnologies. Chapter 6 discusses the indispensability and ethical aspects of animal experiments in nanotechnology and the nanosciences; and Chapter 7 finishes with the conclusions derived from the results of the literature survey.

The survey is completed by an Annex presenting a detailed description of the steps leading to the specification of the scope of the literature survey and of the spelling out of the search request and depicts the different steps of the performance of the literature survey, a Glossary of nanotechnological terms and the list of literature references.

The list of the 164 publications covering in vivo nanotechnological research used as a basis for the literature survey can be found under www.altex.ch.

\section{Scientific topics pursued with animal experiments in the nanosciences and nanotechnologies}

Scientific articles from Germany, France, the United Kingdom, Italy, the Netherlands and Switzerland published between 2004 and 2007 were collected. These are the European countries with the highest public expenditure in nanotechnology (Commission of the European Communities, 2004) and the highest numbers of animals in scientific research as such (Commission Staff Working Document, 2007 and Swiss Federal Veterinary Office - Statistics on Animal Experiments).

The period of 2004 until 2007 (as regards publications dates) was chosen for the literature survey, since initial investigations revealed a considerable increase in the numbers of publications in the areas of nanotechnology and nanomedicine beginning with the year 2004 (see Annex for details on the delineation of the scope of the literature survey and the spelling out of the search query).

Searches in the PubMed database resulted in a total of 164 publications depicting nanotechnological research performed in animal experiments (see Annex for the individual steps of the performance of the literature survey and the determination of relevant articles and under www.altex.ch).

\subsection{Scientific topics of articles depicting research performed in in vivo tests}

The 164 publications depicting research performed with in vivo methods (either alone or in combination with in vitro methods) were assigned to specific scientific fields, such as Cardiology, Oncology, or Neurology. In addition, specific nanotechnological topics addressed in the articles could be discerned. Since the nanotechnological topics appeared significant and decisive for the purpose of the literature study, it was strived to use these for the primary classification of the articles, and the scientific fields of the articles for subsequent sub-classifications.

In accordance with the topics addressed in the articles retrieved, the following categories for specific nanotechnological topics were defined: Drug Delivery, Gene Delivery, Vaccine Delivery/Immunogenicity, Oncology (Photo-, Radio-, Thermotherapy), Imaging Technology, and Tissue Engineering.

Articles depicting research on nanoparticle-based targeted delivery of drugs, genes and vaccines (categories: Drug Delivery, Gene Delivery and Vaccine Delivery/Immunogenicity) aim to exploit the specific physical and chemical characteristics of nanoparticles in order to improve the therapeutic efficiency of medications, for example by reducing the size of conventional or genetic pharmaceuticals or vaccines or by encapsulating them with nanoparticles with surface structures so that biological barriers (such as the blood-brain-barrier, the epidermal barrier or the intestinal barrier) can be overcome or to achieve a targeted delivery of substances to the organ in question: "The use of drug-loaded nanoparticles offers several advantages compared with standard therapeutic strategies such as a higher selectivity in adhesion to and enhance drug penetration into the inflamed tissue" (Lamprecht et al., 2005). In this context, articles were assigned to the category Gene Delivery, if they describe therapeutic interventions with nucleic acid-based therapeutic molecules.

Similarly, articles assigned to the category Oncology (Photo-, Radio-, Thermotherapy) explore the targeted application of magnetic nanoparticles for tumour thermotherapy aiming to specifically introduce magnetic nanoparticles into tumour tissues so that the resulting heating of the body area specifically affects the tumour tissue.

The goal of articles assigned to the category of nanotechnological Imaging Technologies is to develop technologies which enable an evaluation of living tissues on the nanoscale level and to allow the targeted use of nanoparticles as contrast agents for example for Magnetic Resonance Imaging. In articles classified in the category Tissue Engineering (or regenerative medicine), 
the properties of nanoparticles are exploited to improve the biocompatibility and functionality of regenerated tissues, such as bones, cartilage, neurons, and heart tissues. Several articles explored nanotechnologies for tissue engineering in combination with imaging technologies. Further main categories defined for the evaluation were Toxicology covering articles on the toxicological evaluation of nanoparticles and Surgery for articles depicting e.g. surgical methods exploiting nanotechnological developments.

\section{Infobox 2 - Visions on nanomedical research areas (European Technology Platform Nanomedicine, 2005)}

\section{Targeted gene / drug / vaccine delivery}

"The long-term objective of drug delivery systems is the ability to target selected cells and/or receptors within the body. At present, the development of new drug delivery techniques is driven by the need on the one hand to more effectively target drugs to the site of disease... [and] ... to identify novel ways to deliver new classes of pharmaceuticals that cannot be effectively delivered by conventional means.... Already now nanoparticle formulations make use of the fact that an enlarged surface/volume ratio results in enhanced activity. Nanoparticles are also useful as drug carriers for the effective transport of poorly soluble therapeutics. When a drug is suitably encapsulated, in nanoparticulate form, it can be delivered to the appropriate site, released in a controlled way and protected from undergoing premature degradation. ... Such nanoparticulate delivery systems can be used to more effectively treat cancer and a wide range of other diseases, which call for drugs of high potency."

\section{Imaging technologies}

"Target-specific contrast nanostructures [enable] improvements of microscopic and spectroscopic techniques towards ultra-high spatial resolution, molecular resolution and ultra- high sensitivity will provide a better understanding of the cell's complex "machinery" in basic research. ... Advancement in in-vivo diagnostics will also rely on molecular imaging and on minimally invasive, implantable devices. In molecular imaging, the goal is to create highly sensitive, highly reliable detection agents that can also deliver and monitor therapy."

\section{Tissue engineering (regenerative medicine)}

"Nanotechnology can play a pivotal role in the development of cost-effective therapies for in-situ tissue regeneration. This involves not only a deeper understanding of the basic biology of tissue regeneration, but also identifying effective ways to initiate and control the regenerative process. This 'nanobiomimetic' strategy depends on three basic elements: intelligent biomaterials, bioactive signalling molecules, and cells. By 'tailoring' resorbable polymers at the molecular level for specific cellular responses, nanotechnology can assist in the development of biomimetic, intelligent biomaterials. These biomaterials are designed to react positively to changes in the immediate environment, stimulating specific regenerative events at the molecular level, directing cell proliferation, cell differentiation, and extracellular matrix production and organization."

67 documents $(41 \%)$ of the 164 publications depicting nanotechnological or nanomedical research performed in vivo related to the category Drug Delivery, with this nanotechnological topic being the most prominent, followed by the categories Imaging Technology (29 documents; 18\%), Vaccine Delivery \& Immunogenicity (18 documents; 11\%), Gene Delivery and Toxicology (15 documents, each; i.e. $9 \%$, respectively). 8 documents (5\%) were classified under the topic of Tissue Engineering, 6 under Oncology (Photo-, Radio-, Thermotherapy) (4\%), and 4 (2\%) under Surgery. 1 publication each related to Cell Biology and Pulmonology (Tab. 1, Fig. 1).

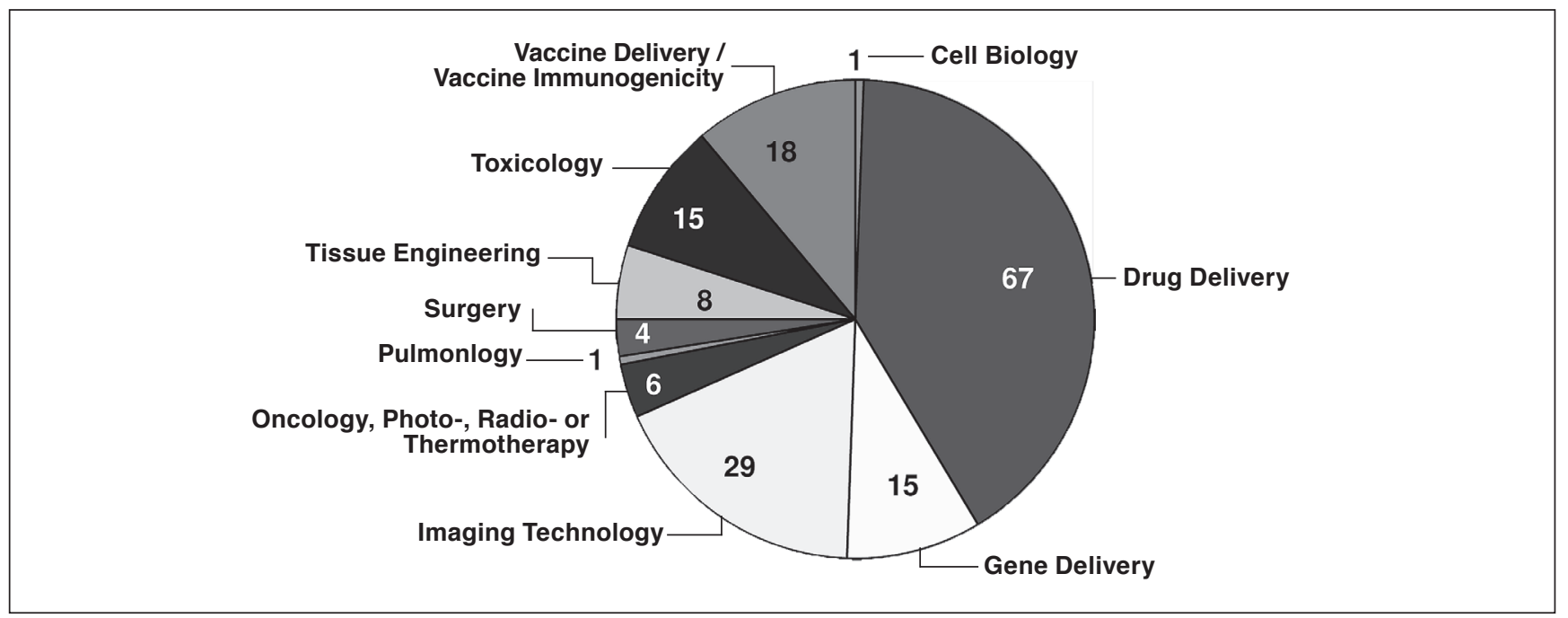

Fig. 1: 164 articles depicting research performed in in vivo classified in accordance to their main topic of research 
Tab. 1: 164 publications in which nanomedical or nanotechnological research performed with in vivo or in vivo \& in vitro methods was described - sorted according to their scientific topic and / or scientific discipline

\begin{tabular}{|c|c|c|c|}
\hline Subject I & Subject II & Subject III & Numbers of publications \\
\hline Cell Biology & & & 1 \\
\hline Drug Delivery & & & 67 \\
\hline Drug Delivery & & & 15 \\
\hline Drug Delivery & Cardiology & & 2 \\
\hline Drug Delivery & Diabetology & & 5 \\
\hline Drug Delivery & Gastroenterology & $\begin{array}{l}1 \times \text { Immunology } \\
1 \times \text { Toxicology }\end{array}$ & 3 \\
\hline Drug Delivery & Hematology & & 2 \\
\hline Drug Delivery & Imaging Technology & $\begin{array}{l}1 \times \text { Neurology } \\
1 \times \text { Oncology }\end{array}$ & 2 \\
\hline Drug Delivery & Immunology & & 2 \\
\hline Drug Delivery & Neurology & & 10 \\
\hline Drug Delivery & Oncology & & 6 \\
\hline Drug Delivery & Oncology & Neurology & 6 \\
\hline Drug Delivery & Oncology & $\begin{array}{l}\text { Other: } \\
1 \times \text { Dermatology } \\
1 \times \text { Hepatology } \\
2 \times \text { Immunology }\end{array}$ & 4 \\
\hline Drug Delivery & Ophthalmology & & 4 \\
\hline Drug Delivery & Otolaryngology & & 1 \\
\hline Drug Delivery & Pulmonology & $1 \times$ Toxicology & 2 \\
\hline Drug Delivery & Toxicology & & 3 \\
\hline Gene Delivery & & & 15 \\
\hline Gene Delivery & & & 4 \\
\hline Gene Delivery & Cardiology & & 1 \\
\hline Gene Delivery & Hepatology & & 1 \\
\hline Gene Delivery & Oncology & $1 \times$ Pulmonology & 7 \\
\hline Gene Delivery & Orthopedics & & 1 \\
\hline Gene Delivery & Pulmonology & & 1 \\
\hline Imaging Technology & & & 29 \\
\hline Imaging Technology & & & 8 \\
\hline Imaging Technology & Cardiology & & 4 \\
\hline Imaging Technology & Cardiology & Tissue Engineering & 4 \\
\hline Imaging Technology & Hepatology & & 1 \\
\hline Imaging Technology & Neurology & $\begin{array}{l}1 \times \text { Immunology } \\
1 \times \text { Tissue Engineering }\end{array}$ & 6 \\
\hline Imaging Technology & Oncology & & 3 \\
\hline Imaging Technology & Orthopedics & & 1 \\
\hline Imaging Technology & Tissue Engineering & & 1 \\
\hline Imaging Technology & Toxicology & & 1 \\
\hline $\begin{array}{l}\text { Oncology / Photo-, Radio- or } \\
\text { Thermotherapy }\end{array}$ & & & 6 \\
\hline Oncology & Thermotherapy & & 4 \\
\hline Oncology & Phototherapy & & 1 \\
\hline Oncology & Radiotherapy & & 1 \\
\hline Pulmonology & & & 1 \\
\hline Surgery & & & 4 \\
\hline Surgery & Ophthalmology & & 1 \\
\hline Surgery & Orthopedics & Dentistry & 1 \\
\hline Surgery & Tissue Implantation & & 1 \\
\hline Surgery & Toxicology & Oncology & 1 \\
\hline
\end{tabular}


Tab. 1 (continued): 164 publications in which nanomedical or nanotechnological research performed with $n$ vivo or in vivo \& in vitro methods was described - sorted according to their scientific topic and / or scientific discipline

\begin{tabular}{|l|l|l|c|}
\hline Subject I & Subject II & Subject III & Numbers of publications \\
\hline Tissue Engineering & & & $\mathbf{8}$ \\
\hline Tissue Engineering & Nerve & & 1 \\
\hline Tissue Engineering & Bone & & 6 \\
\hline Tissue Engineering & Cartilage & & 1 \\
\hline Toxicology & & & 15 \\
\hline Toxicology & & 1 x Cardiology & 4 \\
\hline Toxicology & Ecotoxicology & & 2 \\
\hline Toxicology & Pulmonology & & \\
\hline $\begin{array}{l}\text { Vaccine Delivery I } \\
\text { Vaccine Immunogenicity }\end{array}$ & & & $\mathbf{1 8}$ \\
\hline $\begin{array}{l}\text { Vaccine Delivery I } \\
\text { Vaccine Immunogenicity }\end{array}$ & Human Medicine & 14 \\
\hline $\begin{array}{l}\text { Vaccine Delivery I } \\
\text { Vaccine Immunogenicity }\end{array}$ & Veterinary Medicine & & \\
\hline TOTAL SUM & & & $\mathbf{1 6 4}$ \\
\hline
\end{tabular}

Of the 67 documents assigned to the main category Drug Delivery (Fig. 2), 15 articles addressed general issues relating to nanoparticle-based targeted drug delivery, 10 articles covered targeted drug delivery into the central nervous system as such (e.g. means to overcome the blood-brain-barrier by binding pharmaceutical substances to nanoparticles - category Neurology), 6 articles related to the topic of targeted drug delivery to brain tumours (category Oncology/Brain), and another 6 to general issues of drug delivery for tumour treatment (category Oncology/General). 5 articles addressed the issue of insulin delivery (for instance to improve oral bioavailability - category Diabetology). 4 articles each were assigned to the category Ophthalmology and to the issue of targeted drug delivery to other tumours of the body (Oncology/other, i.e. tumours of the skin, the liver and the immunological system). 3 articles each related to drug delivery in the treatment of gastroenterological diseases (Gastroenterology) and to the toxicity of drug delivery systems (Toxicology). In the figure, the category Other includes 1-2 articles each (altogether a total of 11) that addressed targeted drug delivery for the treatment of disorders of the heart, lung, blood, immune system and otolarynx as well as articles exploring the application of nanoparticles that are both suitable as drug delivery systems and for Imaging Technology.

Of the 15 articles with the primary subject of Gene Delivery (Fig. 3), 7 articles addressed the issue of targeted gene delivery

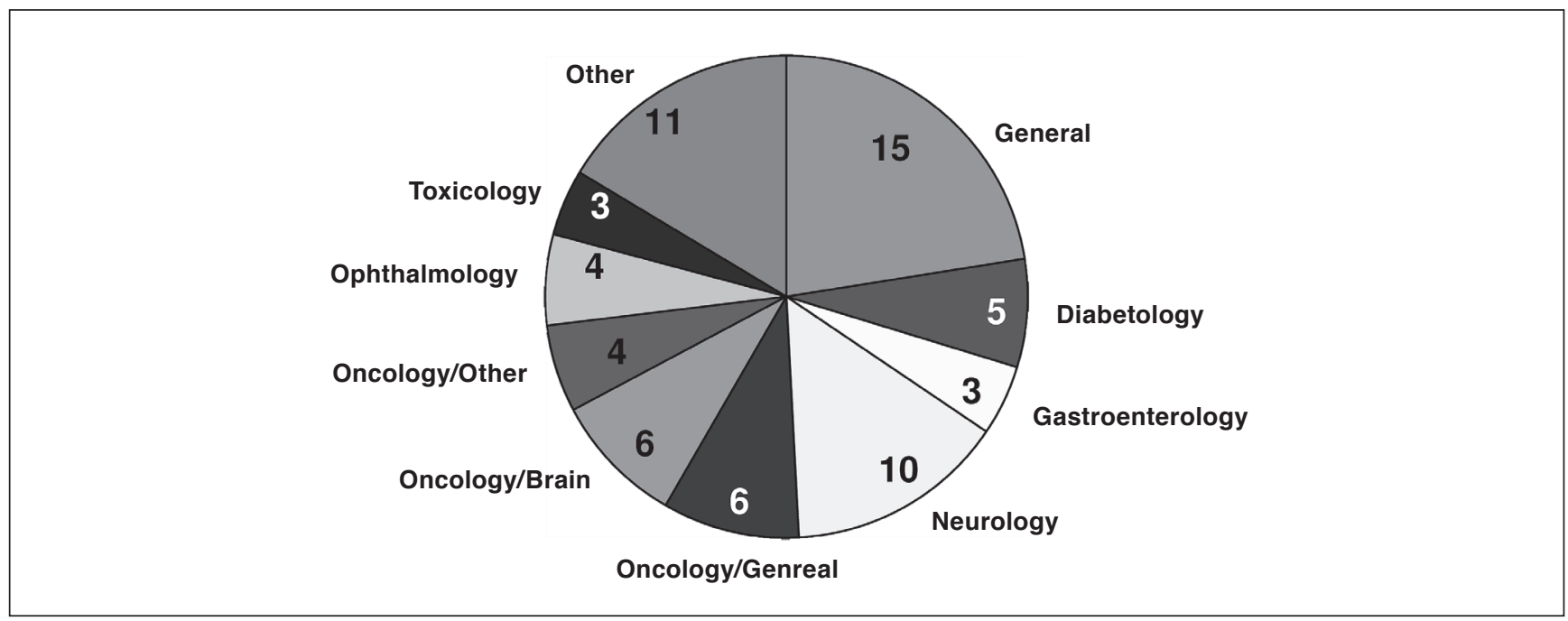

Fig. 2: 67 articles with main topic "drug delivery" sorted in accordance to further topics of research 


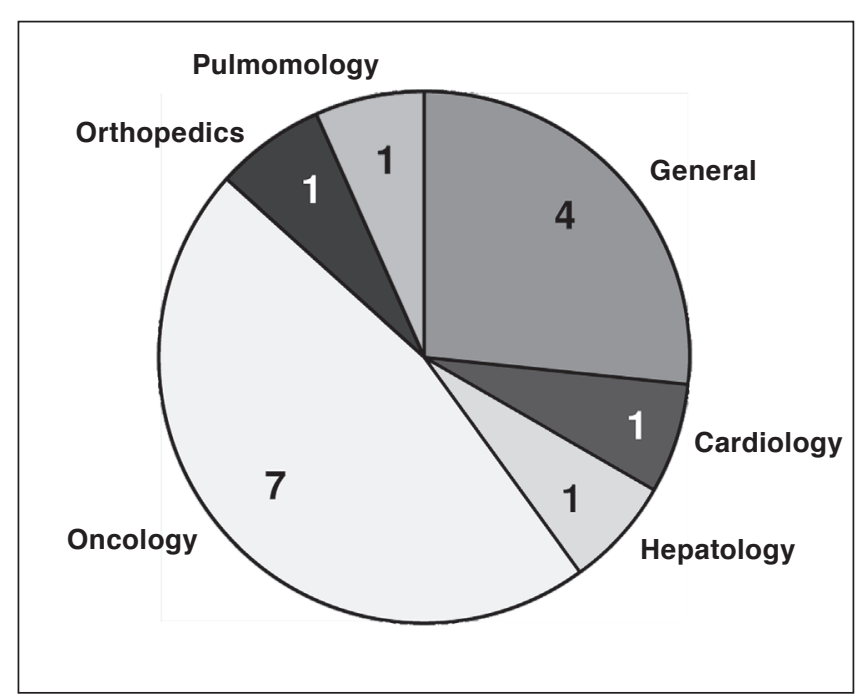

Fig. 3: 15 articles with main topic "gene delivery" sorted in accordance to further topics of research

for the treatment of cancerous diseases (Oncology), 4 articles covered general issues relating to gene delivery, and 1 article each addressed the issues of targeted gene delivery for the treatment of cardiological, hepatological or pulmonological diseases.

Of the 29 articles assigned to the category Imaging Technology (Fig. 4), 8 articles addressed general issues relating to this topic, 6 the imaging of the brain (category Neurology), 3 the imaging of the heart (category Cardiology), another 5 the imaging of the heart during tissue engineering processes, 3 imaging of cancerous tissues (category Oncology) and 1 article each imaging of joints (category Orthopedics) and toxicological issues (category Toxicology) relating to the use of nanoparticles as contrast agents for imaging technologies and during tissue engineering processes.

Of the 8 articles with the main topic of Tissue Engineering (Fig. 5), 6 articles each related to bone tissue engineering, while one article each related to cartilage and neuron tissue engineering. Four of the six articles assigned to the main category of Oncology dealt with issues regarding tumour thermotherapy, while one article each dealt with the radiological and phototoxicological treatment of tumours (radiotherapy and phototherapy). The four articles assigned to the category Surgery were further classified as relating to (one each) Ophthalmology, Orthopedics and Dentistry, Tissue Implantation and Toxicology and Oncology. Four of the 15 articles assigned to the main category of Toxicology were subclassified to cover general toxicological issues, 9 to cover pulmonological issues and two to cover ecotoxicological issues. 14 of the 18 articles covering nanoparticle-based targeted Vaccine Delivery or issues of nanoparticle vaccine immunogenicity addressed vaccines for the treatment of humans, whereas in 4 articles vaccines for veterinary medicine use were studied.

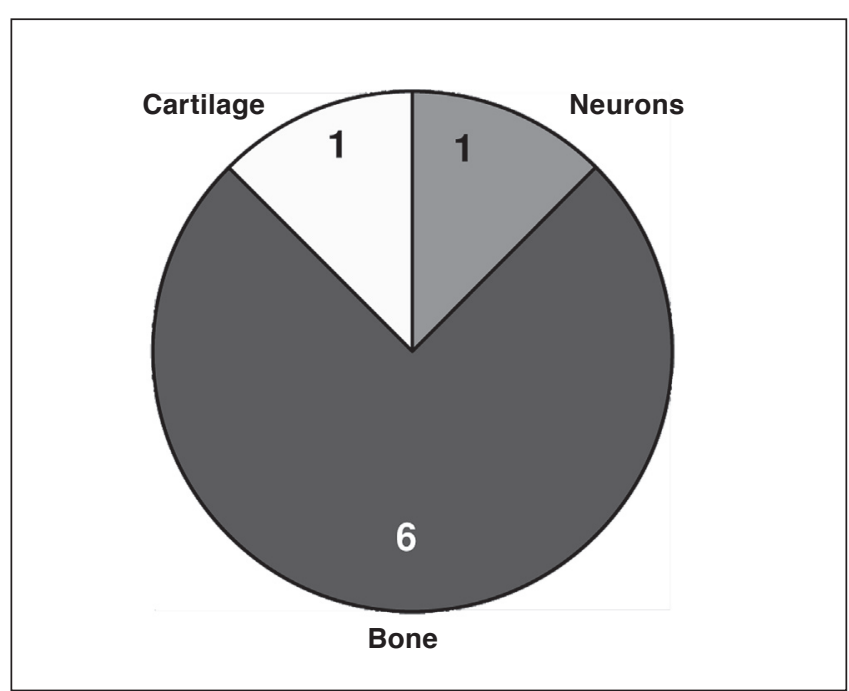

Fig. 5: 8 articles with main topic "tissue engineering" sorted in accordance to specification of type of tissue in question

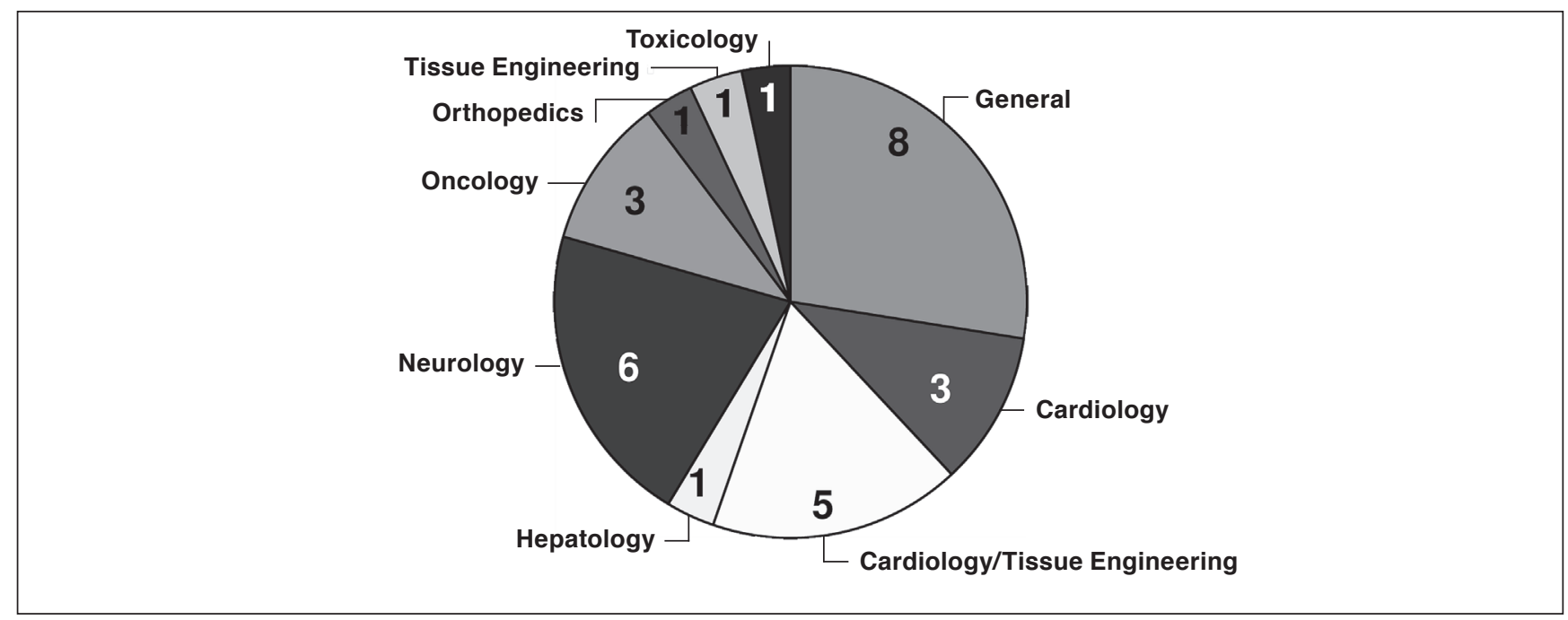

Fig. 4: 29 articles with main topic "imaging technology" sorted in accordance to further topics of research 


\subsection{Animal species used in the in vivo methods depicted in the articles}

In the 164 articles evaluated depicting in vivo research, use of the following species was reported: Mice (transgenic and conventionally bred) -73 articles $(43 \%)$, rats -61 articles $(36 \%)$, rabbits -12 articles (7\%), pigs and minipigs -8 articles (5\%), sheep -4 articles, macaques -3 articles, rainbow trout and horses -2 articles each, dogs, hamsters and guinea pigs -1 article each. Several articles depicted in vivo research using more than one animal species. Therefore the total number of times use of animal species was reported is higher than 164, i.e. 169 (Tab. 2).

\section{Examples of animal experiments performed in nanomedicine and nanotechnology}

In this chapter, examples for animal experiments performed for research in nanomedicine or for the safety testing of nanotechnological products are presented with the aim to provide an overview over the broad spectrum of in vivo test methods in this scientific area. Since there are no standardised animal test methods in fundamental biomedical research such as the topics of research depicted in this literature survey, it was considered necessary to provide concrete examples based upon concrete articles to elucidate the broad spectrum of animal experiments performed in the area of nanomedicine and nanotechnology. Choice of these specific articles is not intended to reflect a specific scientific rating of the research depicted.

\subsection{Drug delivery, cardiology}

Westedt et al. (2007) explored the therapeutic efficiency of catheter-based local delivery of biodegradable nanoparticles

Tab. 2: Number of times in which use of specific animal species was reported in the 164 articles depicting in vivo nanotechnological research

\begin{tabular}{|l|c|c|}
\hline Animal species & $\begin{array}{l}\text { Number of times reported } \\
\text { in the 164 articles } \\
\text { depicting in vivo research }\end{array}$ & Percentage \\
\hline Mice & 73 & 43.0 \\
\hline Rats & 61 & 36.0 \\
\hline Rabbits & 12 & 7.0 \\
\hline Pigs and minipigs & 8 & 5.0 \\
\hline Sheep & 4 & 2.4 \\
\hline Macaques & 3 & 2.0 \\
\hline Rainbow trout & 2 & 1.1 \\
\hline Horses & 2 & 1.1 \\
\hline Dogs & 1 & 0.6 \\
\hline Hamsters & 1 & 0.6 \\
\hline Guinea pigs & 1 & 0.6 \\
\hline Chicken & 1 & 0.6 \\
\hline Total & 169 & 100 \\
\hline
\end{tabular}

with sustained release characteristics in the reduction of arterial restenosis. For this purpose, they loaded nanoparticles ${ }^{* 4}$ with paclitaxel, a pharmaceutical active ingredient also used for the prevention of arterial restenosis, and administered these particles locally to the wall of balloon-injured rabbit iliac arteries using a porous balloon catheter. According to their observations, the treatment with paclitaxel-loaded nanoparticles resulted in a $50 \%$ reduction in neointimal area in vessel segments treated with paclitaxel-loaded nanoparticles compared to control vessel segments.

\subsection{Drug delivery, diabetology}

Damgé et al. (2007) explored the potential of nanoparticle-encapsulated insulin to improve the oral bioavailability of insulin. They studied the therapeutic efficiency of different doses of insulin nanoparticles administered orally by force-feeding in diabetic rats and observed that insulin nanoparticles decreased fasted glycemia in a dose dependent manner. Their studies also showed that insulin nanoparticles increased serum insulin levels and improved the glycemic response to an oral glucose challenge for a prolonged period of time. Additionally, the insulinloaded nanoparticles strongly adhered to the intestinal mucosa and labelled insulin was mainly taken up by the Peyer's patches. The authors conclude that such nanoparticles allow the preservation of insulin's biological activity and, additionally, that the resulting antidiabetic effect can be explained by the mucoadhesive properties of the particles, allowing the intestinal uptake of insulin.

\subsection{Drug delivery, oncology and neurology}

Steiniger et al. (2004) evaluated the therapeutic potential of doxorubicin bound to polysorbate ${ }^{*}$-coated nanoparticles in the treatment of aggressive glioblastomas, which, due to the bloodbrain barrier, are mostly inaccessible to traditional chemotherapy. For this purpose, they implanted glioblastoma tumour cells into rat brains. Next, different groups of rats received doxorubicin in different formulations including doxorubicin bound to polysorbate-coated nanoparticles; and the animals were analyzed for increase of survival time. The authors observed that rats treated with doxorubicin bound to polysorbate-coated nanoparticles had significantly higher survival times compared with all other groups and that over $20 \%$ of the animals in this group showed a long-term remission without indication of neurotoxicity. According to the authors, the results of the study reveal the therapeutic potential of nanoparticle-bound doxorubicin for the treatment of human glioblastoma.

\subsection{Drug delivery, ophthalmology}

In order to study possible treatments of experimental autoimmune uveoretinitis induced by specific antigens in rats, de Kozak et al. (2004) incorporated tamoxifen, a non-steroidal estrogen receptor modulator, into polyethylene glycol-coated nanoparticles. These nanoparticles were then injected into the vitreous cavity of the rats. The authors observed that while the

\footnotetext{
4 Terms marked with an asterisk $\left({ }^{*}\right)$ are explained in the glossary at the end of the article.
} 
injection of free tamoxifen did not alter the course of the experimental autoimmune uveoretinitis, injection of the drug-loaded nanoparticles 1-2 days before the expected onset of the disease resulted in significant inhibition of proliferation of the inflammatory cells or the inflammatory signal molecules. The authors conclude that tamoxifen-loaded nanoparticles may represent a new option for the treatment of experimental uveitis.

\subsection{Gene delivery, oncology}

Small interfering ribonucleic acids (siRNA) are molecules that specifically prevent the expression of their specific genes. Based on previous findings that "anti-RhoA siRNA", when blocking the gene RhoA (a gene indicating a poor prognosis in cancer), inhibited tumour progression, Pillé et al. (2006) evaluated the therapeutic efficiency and safety of such "anti-RhoA siRNA". For this purpose, they transplanted aggressive human breast cancer tissues into nude mice. In order to improve the bioavailability of the "anti-RhoA siRNA", they encapsulated the molecules into special "chitosan-coated polyisohexylcyanoacrylate* nanoparticles". These siRNA were administered every 3 days at doses of 150 or 1500 microgram $/ \mathrm{kg}$ body weight to the nude mice. According to the observations of the authors, the treatment inhibited the growth of tumours by $90 \%$ in the $150-$ microgram group and by even more in the 1500-microgram group. Additionally, they report the therapy to be devoid of toxic effects. The authors suggest that therapeutic interventions with "anti-RhoA siRNA" hold significant promise for the treatment of aggressive cancers.

\subsection{Imaging technology, cardiology}

Five hours after inducing permanent myocardial infarction in rats, Chapon et al. (2005) evaluated infarct size and myocardial viability using three-dimensional in vivo magnetic resonance imaging at 7 Tesla. For this purpose, they successively injected an extracellular paramagnetic contrast agent and intravascular superparamagnetic iron oxide nanoparticles* in the same imaging session. According to the authors, this three-dimensional magnetic resonance imaging protocol using a successive contrast agent injection enabled an accurate characterization of the myocardial infarction volume and allowed the detection of myocardial viability post-infarction in the rats.

\subsection{Imaging technology, cardiology and tissue engineering}

In an attempt to trace the destination of injected cells during regenerative cell replacement therapies after myocardial infarction, Küstermann et al. (2005) investigated whether transplanted stem cells can be identified in mouse heart muscle cells with high-resolution magnetic resonance imaging. For this purpose, the myocardium of mice was injured by cryoinjury or left coronary artery ligation; and heart progenitor cells labelled with ultra-small paramagnetic iron-oxide nanoparticles were transplanted into the myocardium. The precise location of the cells was determined with magnetic resonance imaging and compared with histological tissue sections. The experiments showed that iron nanoparticle-loaded cells could be identified in the mouse heart.
Ruhparwar et al. (2006) also strived to track the fate of bone marrow derived cells transplanted into the myocardium after heart failure and emphasize that this is a prerequisite in order to determine the efficiency of myocardial restoration. For this purpose, they labelled human endothelial progenitor cells with nanoparticles, transplanted them into the ischemic hearts of pigs and used ultra high-field magnetic resonance imaging to track the nanoparticle-labelled cells. The authors were able to identify the cells within the myocardium 4 weeks after transplantation and conclude that magnetically labelled cells transplanted for therapeutic neovascularization or reduction of infarct size in myocardial ischemia can be visualized by magnetic resonance imaging at high-field strengths.

\subsection{Imaging technology, neurology}

With the aim to visualize developing vessel occlusion in focal cerebral ischemia, Kleinschnitz et al. (2005) induced cortical photothrombosis in rats (illumination of the brain for induction of thrombosis), which in addition received superparamagnetic iron oxide (SPIO) ${ }^{*}$ particles intravenously - either simultaneously during the illumination or two hours or one day, respectively, after illumination. According to the authors, early SPIOenhanced magnetic resonance imaging provides a reliable in vivo tool to delineate areas of developing vessel occlusion in experimental cerebral ischemia and identifies vessel thrombosis as one mechanism of secondary infarct growth in photothrombosis. They suggest that this new imaging technique might aid to evaluate antithrombotic treatment strategies in the future.

Dunning et al. (2004) evaluated nanoparticle-based imaging technologies to follow the fates of transplanted Schwann cells and olfactory ensheathing cells, cells which have been shown experimentally to promote axonal regeneration and remyelination in the central nervous system. In an initial, in vitro, step, the cells first were loaded with dextran-coated superparamagnetic iron oxide (SPIO) ${ }^{*}$. Afterwards the scientists injected these cells into focal areas of demyelination in the spinal cord of adult rats. For demyelination, a dorsal laminectomy was performed in the anesthetised animals and the meninges incised to reveal the dorsal funiculus. Ethidium bromide was injected into the dorsal funiculus through the meningeal incision. After 24-48 hours, the animals were anesthetised again, and the spine exposed to $\mathrm{X}$-irradiation. The authors observed both types of transplanted SPIO-labelled cells to produce a characteristic signal reduction in magnetic resonance imaging that correlates closely with areas of remyelination. In addition, the authors report that the SPIO-labelled cells retain their ability to myelinate normally after transplantation.

\subsection{Oncology, thermotherapy}

Jordan et al. (2006) evaluated the therapeutic potential of thermotherapy using so-called superparamagnetic nanoparticles* which, after specific introduction into tumour tissue, are excited by magnetic fields thereby inducing interstitial hyperthermia and thermoablation, the destruction of tumour cells by heat. First, the authors injected glioma cells into the brains of rats in order to induce tumour growth. Different groups of animals received thermotherapy treatments following a intratumoural 
injection of different magnetic fluids. Treatment was carried using a so-called alternating magnetic field applicator system. The effectiveness of treatment was determined by the survival time of the animals and histopathological examinations of the brain and the tumour. Thermotherapy with aminosilane-coated nanoparticles led up to 4.5-fold prolongation of survival over controls, while the dextran-coated particles did not indicate any advantage. The authors conclude that localized interstitial thermotherapy with magnetic nanoparticles has an antitumoural effect on malignant brain tumours and that this method might be a novel strategy for treating malignant glioma, which cannot be treated successfully today.

In order to examine the feasibility of magnetic fluid hyperthermia $(\mathrm{MFH})$ for the treatment of prostate cancer, Johannsen et al. (2004) induced prostate tumours in male rats. The animals either received MFH treatment following intratumoural administration of magnetic fluids or were used as either tumour growth controls for determination of iron distribution in selected organs or as histological controls without MFH treatment. The authors observed that the magnetic fluids infiltrated the prostate and that stable steady-state intratumoural treatment temperatures could be induced. They conclude that these results demonstrate the feasibility of MFH in a prostate cancer model.

\subsection{Surgery, tissue implantation}

Kannan et al. (2007) developed a novel nanocomposite* to be used as silicone implant, for example in breast augmentation procedures, without the risk of capsular contracture prevailing in current silicone implants. These nanocomposites and a conventional siloxane control were implanted into sheep. After implantation, the authors observed minimal inflammation of the nanocomposite within the sheep as compared with the siloxane control. After 36 months, the test items were extracted together with the surrounding tissue for subsequent histological evaluation. The authors conclude that nanocomposites have enhanced interfacial biocompatibility and better biological stability as compared with conventional silicone biomaterials.

\subsection{Tissue engineering, bone}

Thorwarth et al. (2005) examined the de novo bone formation in bony defects following the insertion of autogenous bone alone versus an injectable nanoparticle hydroxyapatite alone and in combination with $25 \%$ autogenous bone. The regenerative potentials of the tested materials were compared with each other using adult domestic pigs with an observation period of 6 months. Based upon the subsequent histological evaluations, the authors conclude that the evaluated nanoparticular hydroxyapatite met the clinical requirements for a bone substitute material. Due to its microstructure, complete resorption was observed.

\subsection{Toxicology, pulmonology}

In order to evaluate the fate of nanoparticles after inhalation, Semmler-Behnke et al. (2007) studied their disappearance from the epithelium by sequential lung retention and clearance and bronchoalveolar lavage (BAL) measurements in rats at various times over 6 months after administration of a single 60- to 100 -min intratracheal inhalation of radiolabeled nanoparticles.
Directly after inhalation, the authors found free nanoparticles in the BAL; later, they were predominantly associated with alveolar macropages (AMs). After 3 weeks, lavageable nanoparticle fractions decreased to 0.06 of the actual nanoparticle lung burden. These particles remained constant at about 0.8 throughout a 6-month period. Three weeks after inhalation, $80 \%$ of the retained radiolabeled nanoparticles were translocated into epithelium and interstitium. The authors conclude that there is a strong size-selective difference in particle immobilization. Furthermore, AM-mediated nanoparticle transport to the larynx originates not only from the nanoparticles retained on the epithelium but also from nanoparticles being re-entrained from the interstitium to the luminal side of epithelium. The authors conclude that nanoparticles are much less phagocytized by AMs than large particles but are effectively removed from the lung surface into the interstitium. Even from these interstitial sites, they undergo AM-mediated long-term nanoparticle clearance to the larynx.

\section{Infobox 3 - Risk assessment of nanotechnological products}

Due to their increased relative surface area and to quantum effects resulting from their small size, nanomaterials are considered to have significantly different properties than the respective bulk materials of the same chemical substances (SCCP, 2007, p. 5). Therefore new challenges are recognized for the safety testing of nanotechnological products in order to adequately address their risks. The European Commission has confirmed the need to identify such risks from the beginning on (Commission of the European Communities, 2004, page 5). As regards regulations to ensure the safety of nanomaterials and nanotechnological products, the European Commission considers current legislation to be adequate to meet this goal, while acknowledging that improvements ought to be made in the implementation of the respective regulations. Furthermore the Commission states that knowledge gaps do exist in regard to how to test the hazardous effects of nanomaterials and that current risk assessment procedures require modification for nanoparticles (Commission of the European Communities, 2007 and 2008a). In its "Research Strategy", the German Government has published a comparable assessment of the challenges to face in determining the toxicological and ecotoxicological effects of nanotechnological products. In principle, nanomaterials can enter an organism via the oral, dermal and inhalation route. Due to their small size, the inhalation route is receiving special attention (German Federal Government, 2007, pages 24-25 and 34).

In light of lacking concrete testing requirements for nanomaterials, the European Commission has published a voluntary Code of Conduct for responsible nanosciences and nanotechnologies $(\mathrm{N} \& \mathrm{~N})$ research (Commission of the European Communities, 2008b). As regards initiatives to develop, promote and implement non-animal testing strategies for the safety testing of nanomaterials and nanoprod- 
ucts, the Code of Conduct states: "Member States, N\&N research funding bodies and organisations should encourage fields of N\&N research with the broadest possible positive impact. A priority should be given to research aiming to protect the public and the environment, consumers or workers and aiming to reduce, refine or replace animal experimentation" (Commission of the European Communities, 2008b, 4.1.13).

On the level of the EU, research on safety aspects of nanoparticles is being performed by the Joint Research Centre (JRC) of the European Commission's Institute for Health and Consumer Protection (IHCP). "The JRC, meanwhile, is focusing on the development and harmonization of methods for the characterization and toxicity testing of manufactured nanomaterials (e.g. particle size measurements, in vitro testing of a representative set of nanomaterials on critical cell lines); related studies on reference materials and dosimetry; studies on the applicability of computational methods for assessing nanoparticle properties, including toxicity; and database development" (Commission of the European Communities, 2007, page 10).

Under the EU's seventh Research Framework Programme, the IHCP has initiated two programmes to develop in vitro assays to determine toxicological effects of nanomaterials, InViTech - In vitro testing technologies and assay automation $^{1}$ and Nanobiotech - NanoBiotechnology for Health ${ }^{2}$ : "An integrated approach combining cell-based in vitro assays with specific radiochemical and physicochemical facilities of the NMI Unit will be applied. Manufactured NanoMaterials (NM) will be synthesised, characterized chemically and physically, and their interaction with biologically relevant entities (DNA, proteins) evaluated. In particular, the changes in biological response brought by the adsorption of these systems on NM will be evaluated. The NM will then be tested for their basal cytotoxicity, carcinogenic potential, genotoxicity, chronic toxicity, development toxicity, reproductive and immunotoxicity using the common in vitro tests used in regulatory toxicology. In addition the mNPs uptake and intracellular distribution will be studied using radio labelled nanoparticles. In collaboration with the QSAR activity of ECB, mechanisms of toxicity will be modelled and analysed to evaluate to potential toxicity of untested nanomaterials."

The political and scientific activities, however, are not directed at developing an entirely non-animal testing strategy for the safety testing of nanomaterials. Instead, it is envisaged to combine non-animal and animal testing (German Federal Government, 2007, page 7-8): "Furthermore, a balance between in vitro and in vivo methods is aimed for, which essentially is being influenced by the significance of

1 http://ec.europa.eu/dgs/jrc/index.cfm?id=1640\&obj_id= PROJECTS0000000003016D2F\&dt_code=ACT\&lang=en 2 http://ec.europa.eu/dgs/jrc/index.cfm?id=1640\&obj_id= PROJECTS0000000003016D3B\&dt_code=ACT\&lang=en

3 original text: „Außerdem wird eine Balance zwischen in vitro- und in vivo-Methoden avisiert, die wesentlich durch die Aussagekraft der in vitro-Methoden beeinflusst wird. Dazu ist eine Validierung der in vitro-Methoden durch in vivo-Methoden erforderlich." the in vitro methods. For this purpose, it is necessary to validate the in vitro methods against the in vivo methods." 3

(Note: This statement completely disregards that the validity of in vivo tests to determine health and environmental effects of nanomaterials is unknown, so that a validation of the in vitro tests against the in vivo tests has to be regarded as scientifically questionable and at the least will prevent the non-animal tests from being better than the in vivo tests.)

Some industrial companies and Societies have also declared their commitment for a safe production of nanoproduts, such as the German Chemicals Industry (VCI, Verband der Chemischen Industrie), which, on 11 March 2008, published a report "Responsible production and use of nanomaterials" 4 . Statements in - singular - scientific publications confirm that chemical companies are addressing the issue of safety testing of nanomaterials and are aiming to avoid animal experiments: "To ensure the product safety of nanomaterials, BASF has initiated an extensive program to study the potential inhalation toxicity of nanosize particles." - "A stepwise testing approach is recommended that also could reduce the number of animals used in testing", (MaHock et al., 2007).

On the level of the OECD, in 2006 a Working Party for Manufactured Nanomaterials (WPMN) was formed, whose main work is carried through six steering groups addressing, amongst other issues, research strategies and testing guidelines for manufactured nanomaterials. One of the WPMN projects aims at exploring alternative test methods in nanotoxicology.

4 http://www.vci.de/default2 cmd shd docnr 122306 rub 809 tma 1 nd . htm

\subsection{Vaccine delivery/immunogenicity, veterinary medicine}

In order to evaluate the immunogenic effects of different Rhodococcus equi ${ }^{5}$ antigen preparations in foals after immunization of the pregnant mares, Cauchard et al. (2004) immunized groups of pregnant mares with the different preparations, one of which receiving a specific so-called $R$. equi VapA protein antigen associated with a water-based nanoparticle adjuvant. The immunogenic endpoints were evaluated during pregnancy in mares, and up to day 45 post-delivery in foals in which $R$. equi infections were recorded in the first 6 months of life. The authors report that pregnant mares immunized with virulent $R$. equi proteins developed higher serum IgG and opsonic activity which were transferred to the foals than either in the whole $R$. equi immunized or the control group. Four foals developed pneumonia in the control group while none in immunized groups. Results support further evaluation of VapA protein antigen associated with a water-based nanoparticle adjuvant as a candidate vaccine for immunization of pregnant mares resulting in passive antibodymediated protection of foals.

\footnotetext{
5 Agent causing respiratory diseases, especially in foal
} 


\section{Estimation of severity of procedures and of scientific benefit of research results}

The scientific articles evaluated in the literature survey present fundamental biomedical research. Unlike in regulatory safety testing, in this scientific realm animal experiments are not standardised, but are designed specifically for each individual research project. As a result, the severity and the scientific benefit of the animal experiments presented in the scientific articles cannot be evaluated as a whole, but have to be discussed on a case-by-case basis.

In the European Union, there is no official classification scheme to assess the severity of procedures or their likely biomedical benefit. Therefore, the severity of the scientific procedures was evaluated in accordance with the classification scheme of the Swiss Federal Agency for Veterinary Affairs (Swiss Federal Veterinary Office. Severity Categories). This scheme distinguishes the Severity Bands 1, 2, and 3 for mild, moderate, and substantial distress inflicted upon laboratory animals and presents an extensive list of examples for procedures on animals assigned to the different severity bands. In classifying severity, the most substantial suffering during the procedure must be taken into account; and the decisive factor is the risk that a degree of suffering might occur due to a procedure even though it might not occur in every single animal.

Several publications describe procedures of implanting glioblastoma tumour cells into rat brains in order to evaluate subsequent treatments with nanoparticle-loaded antitumoural pharmaceuticals or magnetic nanoparticles for magnetic-field induced thermotherapy. Similarly, aggressive breast tumour cells were transplanted into nude mice. In rats, prostate tumours were induced to study the potential of magnetic-nanoparticle based thermotherapy. In accordance with the severity categories of the Swiss Federal Veterinary Office, the induction of tumours inflicts moderate distress, if the experiment is terminated before clinically manifest functional disorders arise. Substantial suffering has to be assumed if the experiment is not terminated before such symptoms occur.

A number of articles describe the induction of permanent myocardial infarction, either in mice, rats or pigs, by performing cryoinjury or left coronary artery ligation after thoracotomy. Ischemic myocardium leads to at least moderate and possibly substantial suffering.

The therapeutic efficiency of catheter-based local delivery of nanoparticle-loaded pharmaceuticals was studied in rabbits with balloon-injured iliac arteries. Photothrombosis in the cortex of the brain of rats was induced to study the application of imaging technologies after focal cerebral ischemia. Likewise, focal spinal cord demyelination was induced in rats with a combined surgical, chemical and radiation-based procedure to study the subsequent application of cell replacement therapies and imaging technologies. During tissue engineering studies, nanocomposites were implanted into sheep, and nanoparticle-based bone tissue replacements were implanted into defects of the bones of pigs. Surgical interventions, such as catheter implantation and bone tissue implantations, are moderately severe; the induction of spinal cord demyelination is substantially distressful. The performance of MRI without other distressing factors is mildly distressful to the animals.
In order to evaluate the oral bioavailability of nanoparticle-encapsulated insulin, diabetic rats were force-fed with the test item. The use of diabetic rats, as such, without further interventions, is moderately distressful.

Ophthalmological nanoparticle-based therapies were tested in rats in which experimental autoimmune uveoretinitis had been induced by specific antigens. Experimental uveoretinitis is assigned to cause substantial suffering.

For toxicological studies, rats received nanoparticles via intratracheal inhalation, and rainbow trout were exposed to nanoparticles in the water. Toxicological studies leading to moderate local or systemic reactions induce moderate suffering.

Nanoparticle-based Rhodococcus equi vaccine delivery and immunogenicity was tested by immunization of pregnant mares and subsequent evaluation if the new-born foals developed $R$. equi pneumonia. Infectious pneumonia in foals is classified as moderately distressful if the infection leads to temporary moderate or chronic mild clinical symptoms. If the disease causes prolonged moderate suffering or is progredient, severe suffering must be assumed.

These examples show that a number of the nanomedical procedures depicted in the articles have to be classified to be at least moderate, but also severely distressful to the animals .

As regards the expected benefit of the procedures, it cannot be disputed that the scientific goals pursued in the articles as such are of high medical importance. Nevertheless, also the benefit of an experiment has to be evaluated on a case-by-case basis, in terms of the concrete benefit likely to accrue as a result of the concrete work depicted in the respective article. Scharmann and Teutsch (1994) point to the difficulty in reliably predicting the scientific benefit of an experiment. They suggest to base the benefit estimation on the likely length of time until the scientific results of the experiment will lead to concrete medical improvements - the shorter this timeframe, the higher the scientific benefit of the experimental results.

A case-by-case evaluation and estimation of the concrete scientific outcome and possible medical benefit of the results of the respective animal experiments including a determination of the relevance of the in vivo results for the situation in humans (for instance by determining which further publications make reference to the 164 publications evaluated in the literature survey) would exceed the scope of this survey, just as a case-by-case evaluation of their indispensability in regard to meeting the scope pursued in the respective projects. On the whole, in a number of scientific nanomedical articles, concrete treatments and diagnostic procedures for human diseases are evaluated; and treatments are found to have a positive effect on the underlying disease. The possible scientific benefit of such articles is assigned to be moderate and possibly high.

\section{Examples for non-animal test methods in nanotechnology and nanomedicine}

A broad spectrum of non-animal test methods are being performed in all scientific areas of nanotechnological and nanomedical research, including those for which animal experiments 
are being conducted. New in vitro technologies and methodologies result from the developments in nanotechnology enabling to cultivate cells under more physiological conditions, allowing automatic high-throughput single-cell evaluations with multiple endpoints and investigations on the level of the single cell - and even a single molecule. Additionally, cell culture methods were recorded allowing studying drug, vaccine and gene delivery systems, the in vitro evaluation of thermotherapy measures, in vitro tissue engineering studies and in vitro nanoparticle toxicology.

\subsection{Cell culture systems to study drug / gene delivery systems}

- General

A number of groups used cell culture systems to study general properties of drug or gene delivery systems, such as the effects of modifying the surface of nanoparticles on their biocompatibility, uptake kinetics and efficiency. Poly(ethyleneglycol) $(\mathrm{PEG})^{*} 6$ improved the biocompatibility of superparamagnetic iron oxide nanoparticles* by resisting protein adsorption and increasing their uptake in human dermal fibroblasts (Gupta and Curtis, 2004). Additionally, modifying the nanoparticle surface induced alterations in cell behaviour distinct from the unmodified particles, suggesting that cell response can be directed via specifically engineered particle surfaces. Similarly, using the macrophage cell line J 774, Martina et al. (2007) found that introducing PEG into the vesicle bilayer of magnetic fluid liposomes (MFL) did reduce the binding efficiency while not altering the kinetics of endocytosis when compared to conventional MFL. Likewise, Garcia-Garcia et al. (2005) demonstrated that PEGylated nanoparticles showed a higher passage through the endothelium of an in vitro blood-brain barrier model, presumably by endocytosis.

Cell entry and intracellular trafficking of dendrimers were studied by Jevprasesphant et al. (2004) using gold-labelled dendrimer* devices and Manunta et al. (2006) using dendriplexes*. Jevprasesphant et al. assessed endocytosis-mediated internalisation across Caco- 2 cell monolayers when the dendrimers were applied to the apical domain; while Manunta et al. found that dendriplexes may have different internalisation and transfection properties in different cells and that caveolae form a preferential route for gene delivery. For a detailed imaging of the cellular processes involved, Martina et al. (2007) and Jevprasesphant et al. (2004) used confocal fluorescence microscopy* a technique allowing three-dimensional reconstructions of topologically complex objects.

Weyermann et al. (2004) evaluated the efficiency of different gene delivery systems in improving the bioavailability of antisense oligonucleotides, which are used as drugs to inhibit gene expression at the transcriptional level. Cellular uptake was measured by a microplate fluorescence quantification method* and, in addition, was visualized in mouse fibroblasts by confocal laser scan microscopy* ${ }^{*}$. An in vitro comparison of the cytotoxicity of the different drug delivery systems was performed

\footnotetext{
4 Terms marked with an asterisk $\left({ }^{*}\right)$ are explained in the glossary at the end of the article.
}

using a MTT assay. The efficiency of the oligonucleotide delivery systems was compared on the level of protein expression by Western blotting.

- Drug delivery to tumour cells

The suitability of nanoparticle drug delivery systems in tumour therapy was also investigated in vitro, in cell culture systems using single cell lines or in complex co-culture systems. Drugs bound to nanoparticles appear to be more effective in tumour therapy than the respective free drugs. In two human tumour cell lines, K562 and MCF7, Laurand et al. (2004) investigated the genetic mechanisms of multidrug resistance and means to circumvent this unwanted effect. In breast carcinoma MDA MB 231 cells, Meryet-Figuières et al. (2007) demonstrated that transfected small interfering RNAs (siRNA) specifically inhibited the expression of Plasminogen-Activator-Inhibitor-1 -Protein, PAI-1, a substance correlated with bad prognosis in breast cancer. In two different neuroblastoma cell lines, Dreis et al. (2007) studied the influence on cell viability of human serum albumin nanoparticles - under investigation as drug delivery systems for cytostatic drugs. The anti-cancer effects of the drug-loaded nanoparticles were increased in comparison to free doxorubicin solutions. Lamprecht and Benoit (2006) studied drug release and cytotoxic effects of lipid nanocapsules* loaded with the chemotherapy drug etoposide in cell cultures of different glioma cell lines.

Meng et al. (2007) developed a complex in vitro brain tumour model system to demonstrate that nanoparticles can accumulate in brain tumour cells and therefore are useful as drug delivery systems. Their in vitro system consisted of a co-culture of DAOY cell brain tumour aggregates and organotypic brain slices. The DAOY aggregates first attached to cerebellum slices and invaded as a unit. Next, single cells in the periphery of the aggregate detached from the DAOY aggregates and gradually replaced normal brain cells. This invasive behaviour of the DAOY cells towards the cerebellum slices showed a similar pattern to that seen in vivo. Confocal micrograph* illustrated that the DAOY cells took up most of the nanoparticles, whereas few nanoparticles were distributed into the brain cells.

\section{- Drug delivery to brain cells}

Different in vitro co-culture systems exist to study nanoparticlemediated passage of drugs through the blood-brain barrier. Models consisting of co-cultures of rat endothelial cells and astrocytes (Garcia-Garcia et al., 2005) and brain capillary endothelial cells and glia cells (Jallouli et al., 2007) were used to study the mechanisms of interaction between colloidal and porous nanoparticles and the blood-brain barrier. In the former study, confocal microscopy showed a higher passage of PEGylated* nanoparticles, presumably by endocytosis. Jallouli et al. found that neutral and cationic nanoparticles had similar degrees of binding and uptake and transcytosis. Both studies conclude that these particles may be a promising tool for drug delivery to the brain.

Drug delivery to pulmonary cells

Brzoska et al. (2004) investigated the suitability of nanoparticles as drug and gene carriers for pulmonary application in vitro 
on primary airway epithelium cells and the cell line 16HBE14o. The nanoparticles were incorporated into bronchial epithelial cells, but provoked little or no cytotoxicity and no inflammation.

- Drug delivery across gastrointestinal cells

Drug delivery across gastrointestinal cells was also investigated in vitro. Beck et al. (2007) prepared dexamethasone in nanoparticle-coated microparticles and studied the influence of such microencapsulation on drug absorption across Caco- 2 cell monolayers. The type of nanocoating material had a significant influence on the drug release profile and on the drug permeation across the cells. The drug absorption from the delivery systems seemed to be controlled mainly by the release rate rather than by epithelial permeability. Des Rieux et al. (2007) used an in vitro model of human intestinal follicle-associated epithelial cell co-cultures to evaluate the influence of intestinal $\mathrm{M}$ cells on the transport of free and nanoparticle-encapsulated helodermin, a model peptide, across the intestinal epithelium. Due to their high endocytosis ability, $M$ cells enhanced the transport of intact helodermin, which was further increased by PEG-ylation* of the nanoparticles used for encapsulating helodermin.

- Transdermal drug and vaccine delivery

Human and animal skin samples were used to study transdermal delivery of vaccines using nanoparticles as carriers. This form of application is considered to be a promising approach to target antigens to antigen-presenting cells. However its efficiency depends on size and/or surface charge of the nanoparticles. Using full thickness pig skin in a diffusion chamber, Kohli and Alpar (2004) found that negatively charged nanoparticles sized 50 or $500 \mathrm{~nm}$ would be ideal carriers for antigen and DNA transport through the skin, while Vogt et al. (2006), using human skin samples, demonstrated that only $40 \mathrm{~nm}$ particles entered epidermal Langerhans cells and could be efficiently used to transcutaneously deliver vaccine compounds via the hair follicle.

\subsection{In vitro evaluation of thermotherapy}

Wilhelm et al. (2007) investigated the efficient killing of malignant prostate tumour cells mediated by intracellular magnetic hyperthermia. After uptake, anionic maghemite nanoparticles were concentrated in intracellular vesicles. Once the cells were subjected to a magnetic field, heat was generated which killed $44 \%$ of the tumour cells in one hour. Repetition of the procedure increased the percentage of dead cells to $80 \%$.

\subsection{In vitro tissue engineering studies}

During tissue engineering studies, organ-specific cells are cultured onto synthetic three-dimensional scaffolds with or without specially modified surface structures. Assessment of the cellscaffold interaction and influences on cellular growth, morphology and adhesion was performed in vitro for smooth muscle cells (Baker et al., 2006), fibroblasts (Berry et al., 2005), osteoblasts (Leclerc et al., 2006), osteoblast-like cells (Monsees et al., 2005; Giannona et al., 2007), dorsal root ganglia explants for axonal regeneration after peripheral nerve injury (Schnell et al., 2007).
Lenhert et al. (2005) used Langmuir-Blodgett lithography* to fabricate regularly spaced grooves of 50 and $150 \mathrm{~nm}$ depths with a periodicity of $500 \mathrm{~nm}$ over several square centimetres on silicon surfaces. These topographies were transferred into polystyrene surfaces by means of nanoimprinting. Primary osteoblasts were cultured on the patterned silicon surfaces. The osteoblasts were observed to align, elongate and migrate parallel to the grooves and thus showed a significant anisotropic (i.e. directionally dependant) behaviour to these surfaces. The authors conclude that this cell behaviour can be used to direct tissue generation on the biomaterial interface.

Perea et al. (2007) present a strategy based on using superparamagnetic nanoparticles* to obtain an endothelial cell lining on the luminal surface of vascular conduits. Human umbilical vein endothelial cells were prelabelled with superparamagnetic nanoparticles. With the help of an electromagnet, the magnetically labelled cells were delivered onto the lumen of a tubular graft. The creation of the endothelium was confirmed non-invasively in a clinical Magnetic Resonance Imaging scanner.

\subsection{In vitro nanoparticle toxicity studies}

In vitro toxicity testing of metallic nanoparticles ( $\mathrm{Co}$ and $\mathrm{Ni}$; Peters et al., 2007), titanium dioxide ( $\mathrm{TiO}(2)$, either alone or in combination with UVA, Reeves et al., 2008), $\mathrm{ZnCl}(2)$ and $\mathrm{FeCl}(3)$ alone or in interaction with nanoparticle carbon black representing particulate air pollution (Wilson et al., 2007) was performed measuring oxidative stress, inflammatory mediators, cytotoxicity and DNA damage. The studies yielded diverging and inconsistent results. This suggests that nanoparticle-induced effects are highly complex and might indicate the need to design new strategies for nanoparticle toxicology (Peters et al., 2007).

Cell culture systems used in the in vitro nanoparticle toxicity studies included human endothelial cells (Peters et al., 2007), goldfish skin cells (GFSk-S1) in a neutral red retention (NRR) assay and a modified Comet assay (Reeves et al., 2008) and J774 cells (Wilson et al., 2007). Using laser scanning microscopy in a triple cell co-culture model of the human airway wall, Gehr et al. (2006) investigated the cellular interaction of nanoparticles with epithelial cells, macrophages and dendritic cells and the resulting cellular responses.

\section{- Cell-free chemical test systems for in vitro nanoparticle} toxicity testing

Different authors determined nanoparticle toxicity in chemical test systems that measure the oxidative potential of the particles. Using a cell-free ascorbate test, Stoeger et al. (2009) showed that the in vivo inflammatory response to different combustionderived nanoparticles can be predicted by chemical determination of their oxidative potential. The oxidative potential of the particles correlated to their surface area, an observation also made by Koike and Kobayashi (2006) who investigated the oxidative effects of different carbon black nanoparticles by measuring consumption of dithiothreitol (DTT) in a cell-free system. Kagan et al. (2006) used a cell-free ascorbate reduction model system to show that the iron content of single-walled carbon nanotubes changes their redox activity. In a cell-free system with sulfuric acid, Guo et al. (2009) revealed synergistic oxida- 
tive effects of carbon black co-exposed with $\mathrm{Fe}_{2} \mathrm{O}_{3}$ particles. Using a fluorogenic probe in a cell-free assay system, Foucaud et al. (2007) studied the mechanism and molecules involved in oxidative stress. The authors compared the influence of different suspension media used to disperse the nanoparticles on the production of reactive oxygen species.

\subsection{Microfluidics* and single cell scale imaging technologies}

Microfluidics is the science of building miniaturized devices with chambers and tunnels with dimensions well below $1 \mathrm{~mm}$ in which microliters or nanoliters of fluids flow and in which cells can be cultured. In such dynamic cultures, microfluidic flows can be controlled and nutrients are continuously fed to the cultured cells while wastes are removed Combined with semiconductor processing technologies, microfluidics systems are being used to develop so-called lab-on-a-chip systems providing an important step towards the replacement of animal testing. Such highly complex cell biochips mimic in vivo tissue architecture complexities and thus enhance the functionality of the cultured cells. Different organ models can be combined in microfluidic systems, such as a liver and a lung organ model, enabling to study "organ interactions" on chip, for example for in vitro toxicity investigations (Baudoin et al., 2007).

Microfluidic techniques also allow studying the physiological properties of single cells, such as single isolated cardiomyocytes (Klauke et al., 2006) and individual suspended fibroblasts (Wottawah et al., 2005). Doublets of cardiomyocytes were isolated to investigate the interactions between two heart muscle cells (Klauke et al., 2007). Single insect cells were used for proteome analysis (Hellmich et al., 2005). Single cells can be trapped, injected, steered, and deposited by means of optical tweezers* (Hellmich et al., 2005) and optical stretchers* (Wottawah et al., 2005).

Valero et al. (2005) present a microfluidic cell trap device for analysis of apoptosis. The microfluidic silicon-glass chip enables the immobilization of cells and real-time monitoring of the cell death cascade. Exposure of cells to different fluorescent dyes allowed to discriminate between viable, apoptotic and necrotic cells.

Nanotechnology even enables investigations on the level of molecules. The calcium flux response to agonists was monitored in situ using Chinese hamster ovary cells (Zhang et al., 2006). Single $\mathrm{Ca}^{2+}$-activated $\mathrm{K}^{+}$channel molecules in the plasma membrane of migrating cells were identified with a method based on dual-colour labelling with quantum dots* (Nechyporuk-Zloy et al., 2006). Using specific quantum dots ${ }^{*}$ in flow cytometry* and/or confocal laser scanning microscopy*, Kahn et al. (2006) demonstrated the expression of the gene CD36 on human monocytic U937 cells and atherosclerotic tissue sections.

Using a nanopipette* ${ }^{*}$ Bruckbauer et al. (2007) developed a method for controlled voltage-driven delivery of individual fluorescently labelled probe molecules to the plasma membrane, which they used for single-molecule fluorescence tracking. Amongst other issues, this method allows applying the probe to predefined regions on the membrane and releasing only one or a few molecules onto the cell surface. The authors observed different diffusion reactions in different cells and were able to analyze the diffusional properties of different subregions of the cell membrane.

Further techniques include spatially modulated illumination fluorescence microscopy ${ }^{*}$ to measure the size of cellular nanostructures* (Martin et al., 2004), time-of-flight secondary ion mass spectrometry (TOF-SIMS)* to generate three-dimensional molecular images of the surface of freeze-dried Xenopus laevis oocytes (Fletcher et al., 2007), semiconductor quantum dots* to track the motion of intracellular proteins in living HeLa cells by single-molecule measurements (Courty et al., 2006), atomic force microscopy* to analyse the human stratum corneum (SC) at a nanometer scale (Gorzelanny et al., 2006) and many others.

In summary, these examples for non-animal test methods in nanotechnology and nanomedicine reveal which new nonanimal methodologies arise due to nanotechnological developments and also which conventional non-animal test methods are being applied in nanotechnological and nanomedical research. Thus, even though a concrete case-by-case evaluation of the indispensability of the animal experiments performed in nanotechnology and nanomedicine would exceed the scope of the study, the examples for non-animal test methods presented in this chapter provide an overview on the broad spectrum of possibilities to pursue research on nanotechnological and nanomedical topics without performing animal experiments.

\section{Discussion of the indispensability and of ethical aspects of animal experiments in nanotechnology}

In nanomedicine and nanotechnology, animal experiments are being performed in pursuance of scientific goals relating to targeted drug, gene or vaccine delivery, with these topics currently encompassing the majority of nanomedical publications retrieved in the literature survey. Further scientific articles depict research regarding nanotechnology-based imaging technologies, magnetic tumour thermotherapy, tissue engineering for regenerative treatments, and the toxicity of nanomaterials ${ }^{*}$. A large proportion of articles addresses the treatment of malignant cancers; however the spectrum of diseases and disorders for which nanotechnological diagnostic and therapeutic procedures are sought for is broad covering all areas of medicine. The scientific topics currently pursued in nanomedicine are of high scientific importance.

Nevertheless, a concrete deducible medical benefit of a specific scientific piece of work cannot be ensured at the time the respective experiment is performed. Oftentimes, the scientific validity or invalidity of an animal experiment is only determined once the substance or procedure of concern is first evaluated in humans. Thus, the expectations laid on the scientific benefit of an experiment can only be realised one day within a certain likelihood. On the other hand however, the distress inflicted upon the animals inevitably occurs when the respective experiment is performed. As was shown, a large number of animal experiments performed in nanotechnology lead to moderate and even substantial distress and suffering of the animals. This balancing of uncertain concrete medical benefit against certain distress and suffering has to be taken 
into account when discussing ethical aspects of the animal experiments depicted.

From the point of view of animal welfare, an ethical dilemma persists whenever man inflicts pain, distress, and suffering to sentient animals. The infliction of moderate and severe distress is an issue of grave concern and implies that scientists should go to great lengths to strive to overcome such experiments. This request to avoid animal experiments is backed up by legal requirements. The EU Treaty of Amsterdam and EU Directive 86/609/ EEC spell out the obligation to strive to overcome the ethical dilemma inherent to animal experiments by actively seeking non-animal test methods and non-animal testing strategies that enable the scientific goals pursued in biomedical research to be sought for without animal experimentation.

It has to be asked whether the animal experiments depicted are truly the only means to answer the scientific questions addressed by nanomedicine and nanotoxicology. Which non-animal testing methods already exist and which further test methods need to be developed in order to prevent in vivo testing in nanotechnology?

An overview on non-animal test methods performed in nanotechnological and nanomedical research revealed a broad spectrum of methodologies applied in a broad spectrum of scientific areas, including those for which animal experiments are currently being performed. New in vitro technologies and methodologies are arising due to the developments in nanotechnology enabling to cultivate cells under more physiological conditions, allowing automatic high-throughput single-cell evaluations with multiple endpoints and investigations on the level of the single cell - and even a single molecule. Additionally, cell culture methods were recorded allowing studying drug, vaccine and gene delivery systems, the in vitro evaluation of thermotherapy measures, in vitro tissue engineering studies and in vitro nanoparticle toxicology.

The overview on non-animal test methods shows that an abundance of possibilities already exists to pursue the scientific goals of nanomedicine without animals. These non-animal test methods open up the way for non-animal research strategies in nanotechnology and nanomedicine. As necessary, they should be supplemented by the development of additional non-animal test methods. Accordingly, it has to be asked whether there are incentives to replace the animal experiments that are currently being performed in nanotechnology. Whereas concrete incentives to develop non-animal test methods in nanotoxicology could be discerned, in fundamental nanomedicine so far no such attempts are to be seen.

\section{Conclusions: Nanotechnology, challenges and chances towards reducing animal testing}

The results of the literature survey show that - from the point of view of animal welfare - there is no "simple answer" to nanotechnology. On the one hand new methodologies are being developed that have a significant potential to improve in vitro research and to open up new research topics for in vitro research. Likewise, currently roughly "only" one fourth of the biomedi- cal research published in scientific journals apparently has been performed in vivo. Nevertheless, considering that nanotechnology is an emerging technology and that research pathways oftentimes begin in vitro before turning to in vivo methods, there is reason to assume that the increase in animal experimentation might still be impending. Additionally, especially as regards animal testing in toxicology, it has to be questioned whether all in vivo work performed ends up being published in scientific journals. Furthermore, the animal experiments depicted are to be classified as moderately and even severely distressful procedures, so that even if the proportion of in vivo research would not increase in future, there is already sufficient ground for serious concern from the point of view of animal welfare. More so, since concrete incentives for non-animal test development, so far are only discernible in the area of safety testing.

Not least because of the new methodological options that nanotechnology, together with other new technologies, offers in the realms of in vitro research by enabling the evaluation of biochemical processes on the level of the single cell, it is time for a paradigm change in fundamental biomedical research. It is time to design new research strategies that do away with animal experimentation altogether and to found scientific progress on non-animal testing strategies instead. Such a paradigm change without doubt is a multidisciplinary scientific challenge involving not only biologists and medical scientists, but also chemists, physicists and engineers - and also politicians and those responsible from regulatory authorities. The goal to avoid animal testing might imply the need to re-design scientific research strategies in the respective biomedical areas. However such a paradigm change would have a unique potential to improve biomedical and toxicological research.

As regards toxicity testing, the US National Research Council has spelled out a paradigm change from in vivo to in vitro testing strategies as a vision for the $21^{\text {st }}$ century (CTTAEA and NRC, 2007): "Change often involves a pivotal event that builds on previous history and opens the door to a new era. Pivotal events in science include the discovery of penicillin, the elucidation of the DNA double helix, and the development of computers. All were marked by inauspicious beginnings followed by unheralded advances over a period of years but ultimately resulted in a pharmacopoeia of life-saving drugs, a map of the human genome, and a personal computer on almost every desk in today's workplace. Toxicity testing is approaching such a scientific pivot point. It is poised to take advantage of the revolutions in biology and biotechnology. Advances in toxicogenomics, bioinformatics, systems biology, epigenetics, and computational toxicology could transform toxicity testing from a system based on wholeanimal testing to one founded primarily on in vitro methods that evaluate changes in biologic processes using cells, cell lines, or cellular components, preferably of human origin."

This vision of the US National Research Council should be followed up and realized with high priority through a coordinated international action plan. At the same time, the same paradigm change should be strived for in fundamental biomedical research as well.

These animal welfare implications of nanotechnology - both the challenges and chances - should be included in any public 
discussions and political activities regarding this emerging area of research, such as when formulating nanotechnology research policies and action plans. Regarding the ethical and social implications of nanotechnology, the European Commission stresses the importance of pursuing an open dialogue with the public from the beginning on: "Any negative impacts on public health, safety or the environment must be addressed upfront and as an integral part of the technological development process... Ethical principles must be adhered to and potential health, safety or environmental risks scientifically studied, also in order to prepare for possible regulation. Societal impacts need to be examined and taken into account. Dialogue with the public is essential to focus attention on issues of real concern rather than 'science fiction' scenarios" (Commission of the European Communities, 2004). In accordance with the legal provisions of the Treaty of Amsterdam and Directive 86/609/EEC, this framework for an open dialogue should be extended to the animal welfare implications of nanotechnology.

Together with European scientists, the European Commission and the EU Member States should be encouraged to initiate an open dialogue to bring about a paradigm change in fundamental biomedical research that turns away from animal experimentation altogether and develops entirely new search strategies to achieve biomedical progress by applying the new biotechnologies in non-animal research.

Additionally, in the case of nanotechnology, the European Commission and the EU Member States should be invited to spell out concrete incentives, for example in research framework programmes, to promote the development of non-animal test methods to study nanoparticle-based targeted drug delivery into the brain, e.g. for the treatment of malignant cancerous diseases and cardiac diseases, but also for the other relevant scientific areas, such as nanotechnological regenerative medicine and imaging diagnostics.

Ultimately, all activities should include the final goal to request a paradigm change to turn from animal experimentation to non-animal research, both in toxicology and in fundamental biomedical research, with appropriate steps for either scientific area. The recently published US National Research Council's "Vision for the $21^{\text {st }}$ century" can serve as an important support for this request.

\section{References}

Note: All websites were accessed in October 2008.

Baker, S. C., Atkin, N., Gunning, P. A. et al. (2006). Characterisation of electrospun polystyrene scaffolds for three-dimensional in vitro biological studies. Biomaterials 27(16), 3136-3146.

Baudoin, R., Corlu, A., Griscom, L. et al. (2007). Trends in the development of microfluidic cell biochips for in vitro hepatotoxicity. Toxicol. In Vitro 21(4), 535-544.

Beck, R. C., Pohlmann, A. R., Hoffmeister, C. et al. (2007). Dexamethasone-loaded nanoparticle-coated microparticles: correlation between in vitro drug release and drug transport across Caco-2 cell monolayers. Eur. J. Pharm. Biopharm. 67 (1), 18-30.

Berry, C. C., Dalby, M. J., McCloy, D. and Affrossman, S. (2005). The fibroblast response to tubes exhibiting internal nanotopography. Biomaterials 26(24), 4985-9492.

British Standards Institution (2005). Glossary in the Publicly Available Specification "Vocabulary - Nanoparticles" PAS 71:2005 of the British Standards Institution (25 May 2005). http://www.bsi-global.com/en/Standards-and-Publications/ Industry-Sectors/Nanotechnologies/PAS-71/

Bruckbauer, A., James, P., Zhou, D. et al. (2007). Nanopipet delivery of individual molecules to cellular compartments for single molecule fluorescence tracking. Biophys. J. 93(9), 3120-3131.

Brzoska, M., Langer, K., Coester, C. et al. (2004). Incorporation of biodegradable nanoparticles into human airway epithelium cells-in vitro study of the suitability as a vehicle for drug or gene delivery in pulmonary diseases. Biochem. Biophys. Res. Commun. 318(2), 562-570.

Cauchard, J., Sevin, C., Ballet, J. J. and Taouji, S. (2004). Foal $\mathrm{IgG}$ and opsonizing anti-Rhodococcus equi antibodies after immunization of pregnant mares with a protective VapA candidate vaccine. Vet. Microbiol. 104(1-2), 73-81.

Chapon, C., Franconi, F., Lemaire, L. et al. (2005). Volumetric assessment of myocardial viability in rats using 3D double contrast enhanced T1 and T2-weighted MRI. MAGMA 18(6), 302-308.

Commission of the European Communities (2004). Communication from the Commission (2004) - towards a European Strategy for Nanotechnology. COM(2004)338 from 12 May 2004. ftp://ftp.cordis.europa.eu/pub/nanotechnology/docs/ nano_com_en.pdf

Commission of the European Communities (2005). Communication from the Commission to the Council, the European Parliament and the European Economic and Social Committee - Nanosciences and nanotechnologies: An action plan for Europe 2005-2009. COM(2005)243 from 7 June 2005. ftp:// ftp.cordis.europa.eu/pub/nanotechnology/docs/action_plan_ brochure.pdf

Commission of the European Communities (2007). Communication from the Commission (2007) to the Council, the European Parliament and the European Economic and Social Committee - Nanosciences and nanotechnologies: an action plan for Europe 2005 - 2009. First implementation report 2005-2007. COM 2007 (505) final from 6 September 2007. ftp://ftp.cordis.europa.eu/pub/nanotechnology/docs/ com_2007_0505_f_en.pdf

Commission of the European Communities (2008a). Communication from the Commission to the European Parliament, the Council and the European economic and social committee, regulatory aspects of nanomaterials. COM (2008) 366 final from 17 June 2008. http://eur-lex .europa.eu/LexUriServ/LexUriServ.do?uri=COM:2008:0366:FIN:EN:PDF

Commission of the European Communities (2008b). Commission Recommendation on a Code of Conduct for responsible Nanosciences and nanotechnologies research. C(2008) $424 \mathrm{fi-}$ nal from 7 February 2008. ftp://ftp.cordis.europa.eu/pub/fp7/ 
docs/nanocode-recommendation.pdf

Commission Staff Working Document (2007). Annex to the: Report from the Commission to the council and the European Parliament, Fifth Report on the Statistics on the Number of Animals used for Experimental and other Scientific Purposes in the Member States of the European Union. SEC(2007)1455 from 5 November 2007. http://ec.europa.eu/environment/ chemicals/lab_animals/pdf/staff_work_doc_sec1455.pdf

Council Directive 86/609/EEC of 24 November 1986 on the approximation of laws, regulations and administrative provisions of the Member States regarding the protection of animals used for experimental and other scientific purposes. Official Journal L 358, 1. 28 December 1986. http://eur-lex.europa.eu/LexUriServ/LexUriServ.do?uri=CELEX:31986L0609:EN:HTML

Courty, S., Luccardini, C., Bellaiche, Y. et al. (2006). Tracking individual kinesin motors in living cells using single quantum-dot imaging. Nano Lett. 6(7), 1491-1495.

CTTAEA and NRC (2007). Committee on Toxicity Testing and Assessment of Environmental Agents, US National Research Council. Toxicity Testing in the 21st Century: A Vision and a Strategy (216pp.). The National Academies Press. http:// www.nap.edu/catalog.php?record_id=11970\#toc

Damgé, C., Maincent, P. and Ubrich, N. (2007). Oral delivery of insulin associated to polymeric nanoparticles in diabetic rats. J. Control. Release 117(2), 163-170.

de Kozak, Y., Andrieux, K, Villarroya, H. et al. (2004). Intraocular injection of tamoxifen-loaded nanoparticles: a new treatment of experimental autoimmune uveoretinitis. Eur. J. Immunol. 34(12), 2-12.

des Rieux, A., Fievez, V., Momtaz, M. et al. (2007). Helodermin-loaded nanoparticles: characterization and transport across an in vitro model of the follicle-associated epithelium. J. Control. Release 118 (3), 294-302.

Dreis, S., Rothweiler, F., Michaelis, M., et al. (2007). Preparation, characterisation and maintenance of drug efficacy of doxorubicin-loaded human serum albumin (HSA) nanoparticles. Int. J. Pharm. 341 (1-2), 207-214.

Dunning, M. D., Lakatos, A., Loizou, L. et al. (2004). Superparamagnetic iron oxide-labeled Schwann cells and olfactory ensheathing cells can be traced in vivo by magnetic resonance imaging and retain functional properties after transplantation into the CNS. J. Neurosci. 24(44), 9799-9810.

European Technology Platform Nanomedicine (2005). Vision Paper and Basis for a Strategic Research Agenda for NanoMedicine, September 2005. http://cordis.europa.eu/nanotechnology/nanomedicine.htm

Foucaud, L., Wilson, M. R., Brown, D. M. and Stone, V. (2007). Measurement of reactive species production by nanoparticles prepared in biologically relevant media. Toxicol. Lett. 174 (1-3), 1-9.

Fletcher, J. S., Lockyer, N. P., Vaidyanathan, S. and Vickerman, J. C. (2007). TOF-SIMS 3D Biomolecular Imaging of Xenopus laevis Oocytes Using Buckminsterfullerene $(\mathrm{C}(60))$ Primary Ions. Anal. Chem. 79(6), 2199-2206.

Garcia-Garcia, E., Gil, S., Andrieux, K. et al. (2005). A relevant in vitro rat model for the evaluation of blood-brain barrier translocation of nanoparticles. Cell. Mol. Life Sci. 62(12),
1400-1408.

Gehr, P., Blank, F. and Rothen-Rutishauser, B. M. (2006). Fate of inhaled particles after interaction with the lung surface. Paediatr. Respir. Rev. 7 Suppl. 1, S73-S75.

German Federal Government (2007). Research Strategy Nanotechnology, December 2007. (Forschungsstrategie Nanotechnologie der Deutschen Bundesregierung. Nanotechnologie: Gesundheits- und Umweltrisiken von Nanomaterialien - eine Forschungsstrategie. Bundesanstalt für Arbeitsschutz und Arbeitsmedizin, Bundesinstitut für Risikobewertung, Umweltbundesamt). http://www.bmu.de/files/pdfs/allgemein/application/pdf/nano_forschungsstrategie.pdf

Giannona, S., Firkowska, I., Rojas-Chapana, J. and Giersig, M. (2007). Vertically aligned carbon nanotubes as cytocompatible material for enhanced adhesion and proliferation of osteoblast-like cells. J. Nanosci. Nanotechnol. 7(4-5), 16791683.

Gorzelanny, C., Goerge, T., Schnaeker, E. M. et al. (2006). Atomic force microscopy as an innovative tool for nanoanalysis of native stratum corneum. Exp. Dermatol. 15(5), 387-391.

Guo, B., Zebda, R., Drake, S. J. and Sayes, C. M. (2009). Synergistic effect of co-exposure to carbon black and Fe2O3 nanoparticles on oxidative stress in cultured lung epithelial cells. Part. Fibre Toxicol. 6, 4.

Gupta, A. K. and Curtis, A. S. (2004). Surface modified superparamagnetic nanoparticles for drug delivery: interaction studies with human fibroblasts in culture. J.Mater. Sci. Mater. Med. 15(4), 493-496.

Hellmich, W., Pelargus, C., Leffhalm, K. et al. (2005). Single cell manipulation, analytics, and label-free protein detection in microfluidic devices for systems nanobiology. Electrophoresis 26(19), 3689-3696.

Jallouli, Y., Paillard, A., Chang, J. et al. (2007). Influence of surface charge and inner composition of porous nanoparticles to cross blood-brain barrier in vitro. Int. J. Pharm. 344(1-2), 103-109.

Jevprasesphant, R., Penny, J., Attwood, D. and D'Emanuele, A. (2004). Transport of dendrimer nanocarriers through epithelial cells via the transcellular route. J. Control. Release 97(2), 259-267.

Jordan, A., Scholz, R., Maier-Hauff, K. et al. (2006). The effect of thermotherapy using magnetic nanoparticles on rat malignant glioma. J. Neurooncol. 78(1), 7-14.

Johannsen, M., Jordan, A., Scholz, R. et al. (2004). Evaluation of magnetic fluid hyperthermia in a standard rat model of prostate cancer. J. Endourol. 18(5), 495-500.

Kagan, V. E., Tyurina, Y. Y., Tyurin, V. A. et al. (2006). Direct and indirect effects of single walled carbon nanotubes on RAW 264.7 macrophages: role of iron. Toxicol. Lett. 165 (1), 88-100.

Kahn, E., Vejux, A., Ménétrier, F. et al. (2006). Analysis of CD36 expression on human monocytic cells and atherosclerotic tissue sections with quantum dots: investigation by flow cytometry and spectral imaging microscopy. Anal. Quant. Cytol. Histol. 28(1), 14-26.

Kannan, R. Y., Salacinski, H. J., Ghanavi, J. E. et al. (2007). 
Silsesquioxane nanocomposites as tissue implants. Plast. Reconstr. Surg. 119(6), 1653-1662.

Klauke, N., Smith, G. L. and Cooper, J. M. (2006). Extracellular recordings of field potentials from single cardiomyocytes. Biophys. J. 91(7), 2543-2551.

Klauke, N, Smith, G. L. and Cooper, J. M. (2007). Microfluidic systems to examine intercellular coupling of pairs of cardiac myocytes. Lab. Chip 7(6), 731-739.

Kleinschnitz, C., Schütz, A., Nölte, I. et al. (2005). In vivo detection of developing vessel occlusion in photothrombotic ischemic brain lesions in the rat by iron particle enhanced MRI. J. Cereb. Blood Flow Metab. 25(11), 1548-1555.

Kohli, A. K. and Alpar, H. O. (2004). Potential use of nanoparticles for transcutaneous vaccine delivery: effect of particle size and charge. Int. J. Pharm. 275(1-2), 13-17.

Koike, E. and Kobayashi, T. (2006). Chemical and biological oxidative effects of carbon black nanoparticles. Chemosphere 65 (6), 946-951.

Küstermann, E., Roell, W., Breitbach, M. et al. (2005). Stem cell implantation in ischemic mouse heart: a high-resolution magnetic resonance imaging investigation. NMR Biomed. 18(6), 362-370.

Lamprecht, A., Yamamoto, H., Takeuchi, H. and Kawashima, Y. (2005). Nanoparticles enhance therapeutic efficiency by selectively increased local drug dose in experimental colitis in rats. J. Pharmacol. Exp. Ther. 315(1), 196-202.

Lamprecht, A. and Benoit, J. P. (2006). Etoposide nanocarriers suppress glioma cell growth by intracellular drug delivery and simultaneous P-glycoprotein inhibition. J. Control. Release 112(2), 208-213.

Laurand, A., Laroche-Clary, A., Larrue, A. et al. (2004). Quantification of the expression of multidrug resistance-related genes in human tumour cell lines grown with free doxorubicin or doxorubicin encapsulated in polyisohexylcyanoacrylate nanospheres. Anticancer Res. 24(6), 3781-3788.

Leclerc, E., David, B., Griscom, L. et al. (2006). Study of osteoblastic cells in a microfluidic environment. Biomaterials 27(4), 586-595.

Lenhert, S., Meier, M. B., Meyer, U. et al. (2005). Osteoblast alignment, elongation and migration on grooved polystyrene surfaces patterned by Langmuir-Blodgett lithography. Biomaterials 26(5), 563-570.

Ma-Hock, L., Gamer, A. O., Landsiedel, R. et al. (2007). Generation and characterization of test atmospheres with nanomaterials. Inhal. Toxicol. 19(10), 833-848.

Manunta, M., Nichols, B. J., Tan, P. H. et al. (2006). Gene delivery by dendrimers operates via different pathways in different cells, but is enhanced by the presence of caveolin. J. Immunol. Methods 314(1-2), 134-146.

Martin, S., Failla, A. V., Spöri, U. et al. (2004). Measuring the size of biological nanostructures with spatially modulated illumination microscopy. Mol. Biol. Cell 15(5), 2449-2455.

Martina, M. S., Nicolas, V., Wilhelm, C. et al. (2007). The in vitro kinetics of the interactions between PEG-ylated magnetic-fluid-loaded liposomes and macrophages. Biomaterials 28(28), 4143-4153.

Meng, W., Kallinteri, P., Walker, D. A. et al. (2007). Evalua- tion of poly (glycerol-adipate) nanoparticle uptake in an in vitro 3-d brain tumor co-culture model. Exp. Biol. Med. (Maywood) 232(8), 1100-1108.

Meryet-Figuières, M., Resina, S., Lavigne, C. et al. (2007). Inhibition of PAI-1 expression in breast cancer carcinoma cells by siRNA at nanomolar range. Biochimie 89(10), 1228-1233.

Monsees, T. K., Barth, K., Tippelt, S. et al. (2005). Effects of different titanium alloys and nanosize surface patterning on adhesion, differentiation, and orientation of osteoblast-like cells. Cells Tissues Organs 180(2), 81-95.

Nechyporuk-Zloy, V., Stock, C., Schillers, H. et al. (2006). Single plasma membrane $\mathrm{K}+$ channel detection by using dualcolor quantum dot labeling. Am. J. Physiol. Cell. Physiol. 291(2), C266-C269.

Perea, H., Aigner, J., Heverhagen, J. T. et al. (2007). Vascular tissue engineering with magnetic nanoparticles: seeing deeper. J. Tissue Eng. Regen. Med. 1(4), 318-321.

Peters, K., Unger, R. E., Gatti, A. M. et al. (2007). Metallic nanoparticles exhibit paradoxical effects on oxidative stress and pro-inflammatory response in endothelial cells in vitro. Int. J. Immunopathol. Pharmacol. 20(4), 685-695.

Pillé, J. Y., Li, H., Blot, E. et al. (2006). Intravenous delivery of anti-RhoA small interfering RNA loaded in nanoparticles of chitosan in mice: safety and efficacy in xenografted aggressive breast cancer. Hum. Gene Ther. 17(10), 1019-1026.

Reeves, J. F., Davies, S. J., Dodd, N. J. and Jha, A. N. (2008). Hydroxyl radicals $(\mathrm{OH})$ are associated with titanium dioxide $(\mathrm{TiO}(2))$ nanoparticle-induced cytotoxicity and oxidative DNA damage in fish cells. Mutat. Res. 640 (1-2), 113-122.

Ruhparwar, A., Ghodsizad, A., Niehaus, M. et al. (2006). Clinically applicable 7-Tesla magnetic resonance visualization of transplanted human adult stem cells labeled with CliniMACS nanoparticles. Thorac. Cardiovasc. Surg. 54(7), 447-451.

SCCP (2007). Scientific Committee on Consumer Products (SC$\mathrm{CP})$. Opinion on safety of nanomaterials in cosmetic products. SCCP/1147/07 from 18 December 2007. http://ec.europa.eu/ health/ph_risk/committees/04_sccp/docs/sccp_o_123.pdf

Scharmann, W. and Teutsch, G. (1994). Zur ethischen Abwägung von Tierversuchen [Ethical considerations of animal experiments]. ALTEX 11(4), 191-198.

Schnell, E., Klinkhammer, K., Balzer, S. et al. (2007): Guidance of glial cell migration and axonal growth on electrospun nanofibers of poly-epsilon-caprolactone and a collagen/polyepsilon-caprolactone blend. Biomaterials 28(19), 3012-3025.

Semmler-Behnke, M., Takenaka, S., Fertsch, S. et al. (2007). Efficient Elimination of Inhaled Nanoparticles from the Alveolar Region: Evidence for Interstitial Uptake and Subsequent Reentrainment onto Airways Epithelium. Environ. Health. Perspect. 115(5), 728-733.

Steiniger, S. C., Kreuter, J., Khalansky, A. S. et al. (2004). Chemotherapy of glioblastoma in rats using doxorubicinloaded nanoparticles. Int. J. Cancer 109(5), 759-767.

Stoeger, T., Takenaka, S., Frankenberger, B. et al. (2009). Deducing in vivo toxicity of combustion-derived nanoparticles from a cell-free oxidative potency assay and metabolic activation of organic compounds. Environ. Health Perspect. 117 (1), 54-60. 
Swiss Federal Government (2005). Tierschutzgesetz [Federal Act on Animal Protection] from 16 December 2005 (14 pp.). http://www.admin.ch/ch/d/ff/2006/327.pdf

Swiss Federal Veterinary Office. Severity Categories. Bundesamt für Veterinärwesen, Schweiz. Einteilung von Tierversuchen nach Schweregraden vor Versuchsbeginn (Belastungskategorien). Allgemeine Leitsätze und Beispiele zur analogen Klassierung weiterer Versuche. Information Tierschutz 1.04. http://www.bvet.admin.ch/themen/tierschutz/00777/00778/ index.html?lang=de

Swiss Federal Veterinary Office. Statistics on Animal Experiments. Statistik Tierversuche. http://www.tv-statistik.bvet. admin.ch.

Thorwarth, M., Schultze-Mosgau, S., Kessler, P. et al. (2005). Bone regeneration in osseous defects using a resorbable nanoparticular hydroxyapatite. J. Oral Maxillofac. Surg. 63(11), 1626-1633.

Treaty of Amsterdam amending the Treaty on European Union, the Treaties establishing the European Communities and related acts. Protocol on Protection and Welfare of Animals. Official Journal C 340, 10. November 1997. http://eur-lex .europa. eu/en/treaties/dat/11997D/htm/11997D.html\#0110010013

Valero, A., Merino, F., Wolbers, F. et al. (2005). Apoptotic cell death dynamics of HL60 cells studied using a microfluidic cell trap device. Lab. Chip 5 (1), 49-55.

Vogt, A, Combadiere, B., Hadam, S. et al. (2006). 40 nm, but not 750 or $1,500 \mathrm{~nm}$, nanoparticles enter epidermal CD1a+ cells after transcutaneous application on human skin. J. Invest. Dermatol. 126(6), 1316-1322.

Westedt, U., Kalinowski, M., Wittmar, M. et al. (2007). Poly(vinyl alcohol)-graft-poly(lactide-co-glycolide) nanoparticles for local delivery of paclitaxel for restenosis treatment. J. Control. Release 119(1), 41-51.

Weyermann, J., Lochmann, D. and Zimmer, A. (2004). Comparison of antisense oligonucleotide drug delivery systems. $J$. Control. Release 100(3), 411-423.
Wilhelm, C., Fortin, J. P. and Gazeau, F. (2007). Tumour cell toxicity of intracellular hyperthermia mediated by magnetic nanoparticles. J. Nanosci. Nanotechnol. 7(8), 2933-2937.

Wilson, M. R., Foucaud, L., Barlow, P. G. et al. (2007). Nanoparticle interactions with zinc and iron: Implications for toxicology and inflammation. Toxicol. Appl. Pharmacol. 225(1), 80-89.

Wottawah, F., Schinkinger, S., Lincoln, B. et al. (2005). Characterizing single suspended cells by optorheology. Acta Biomater. 1(3), 263-271.

Zhang, X., Yin, H., Cooper, J. M. and Haswell, S. J. (2006). A microfluidic-based system for analysis of single cells based on Ca2+ flux. Electrophoresis 27(24), 5093-5100.

\section{Acknowledgements}

I would like to thank the Foundation Animalfree Research, $\mathrm{Zu}$ rich, Switzerland, for funding and supporting the performance of this literature survey. Special acknowledgements are addressed to Ms. Claudia Mertens and Mr. Peter Krepper, Co-Presidents of the Board of Animalfree Research, for a valuable exchange of views during the performance of the study. I am also indebted to Dr. Stefanie Schindler, research assistant of Animalfree Research, for her detailed commenting on the final version of the survey.

\section{Correspondence to}

Dr. med. vet. Ursula G. Sauer

Scientific Consultancy - Animal Welfare

Hallstattfeld 16

85579 Neubiberg

Germany

Tel.: +49-89-66090717

e-mail: ursula.sauer@sauerug.de

\section{Annex - Specification of the scope of the literature survey and performance of literature search}

\section{Scope of the literature survey}

An initial Medline literature search ${ }^{7}$ using the search term "(nanoparticles OR nanomaterials) AND animals" without oneby-one evaluation of the publications retrieved resulted in a total of 2,695 publications. Only singular publications were reported per year up until 1997; whereas between 16 and 25 publications were found per year from 1998 until 2001. Since the year 2002, a continuous increase of published articles per year can be observed ranging from 40 publications for the year 2002 up to 770 publications for the year 2006 and 892 publications for 2007 (Fig. 6, excluding the years up until 1997).

Due to the large number of publications retrieved as a result of this initial investigation, it was considered necessary to narrow down the relevant search realm to a manageable and at the same time representative area, while ensuring that from within this realm the highest possible amount of relevant documents would be retrieved.

For this purpose, the following decisions were made:

7 All literature searches were performed with the search engines GoPubMed, www.gopubmed.com and Go3R, www.go3r.org 
Extension of the search term "nanoparticles and nanomaterials" in order to retrieve the highest possible amount of relevant documents

In accordance with vocabulary from the Glossary in the Publicly Available Specification "Vocabulary - Nanoparticles" PAS 71:2005 of the British Standards Institution (2005), the following search phrase was chosen to search for relevant publications from the areas of nanotechnology and nanomedicine: "nanotechnology OR nanobiotechnology OR nanomedicine OR nanoparticle OR nanomaterial".

\section{Narrowing down of relevant realm for literature search as regards countries of origin and years of publication of articles}

The literature survey aims to provide an overview on animal experiments performed in European Countries, in order to spell out concrete recommendations to the EU, the EU Member States and other European Countries for the specific promotion of the development of alternative methods for specific research goals.

In accordance with Commission of the European Communities (2004), Germany, France, United Kingdom, Italy, Netherlands and Switzerland are the six European Countries (EU Member States and Associated Countries) having the highest level of public expenditure in the area of nanotechnology and nanomedicine and comprise the bulk of national public expenditure in Europe.

It is to be noted that the respective figure from Commission of the European Communities (2004) lists the public expenditure on nanotechnology in Switzerland together with public funds in Iceland and Norway. However, for Iceland no articles on nanotechnology were retrieved with the search request spelled out for the literature survey (see below) and for Norway a total of 7 articles on nanotechnology. For Switzerland, on the other hand, a total of 92 such documents were retrieved. Therefore it was considered adequate to include publications from Switzerland, but not from Iceland or Norway in the scope of the literature survey.

Germany, France, the United Kingdom, Italy, the Netherlands and Switzerland are also those European nations with regularly report the highest numbers of animals used for scientific purposes (Commission Staff Working Document, 2007 and Swiss Federal Veterinary Office - Statistics on Animal Experiments):

Regarding the numbers of animals used in the EU member states, Commission Staff Working Document (2007), reporting on the numbers of animals used in 2005 (with the exception of France reporting on the numbers from 2004), lists France (2,325,398 animals), the United Kingdom (1,874,207 animals), Germany (1,822,424 animals), Italy (896,966 animals), the Netherlands (531,199 animals) - and Greece - as the EU Member States with the highest numbers of animals used for scientific purposes - with an EU-wide a total of 12,117,583 animals. In Switzerland, a total of 704,129 animals were reported for the year 2005 (Swiss Federal Veterinary Office - Statistics on Animal Experiments).

As regards Greece, the use of 926,092 laboratory animals was reported for the year 2005, of which 901,300 were fish. Of these fish, $99.86 \%$ were used for "studies specific to animal diseases" in the area of "research and development of medical, dental and veterinary products and appliances, not including toxicological studies". Therefore the search request spelled out for the literature survey (see below) was performed for Greece resulted in a total of 12 articles on nanotechnology for the years 2004-2007 altogether. Due to this limited amount of retrievals - and since Greece was not listed as one of the EU Member States with considerable public funding in the areas of nanotechnology or nanomedicine, it was considered adequate to exempt Greece from the scope of the literature survey in spite of its high numbers of animals used in research.

\section{On behalf of these considerations, it was decided to perform the literature survey with scientific publications from Germany, France, the United Kingdom, Italy, the Netherlands and Switzerland.}

Since the initial investigation (see Fig. 6 above) revealed a considerable increase in the numbers of publications in the areas of nanotechnology and nanomedicine beginning with the year 2004, the period of 2004 until 2007 (as regards publications dates) was chosen for the literature survey.

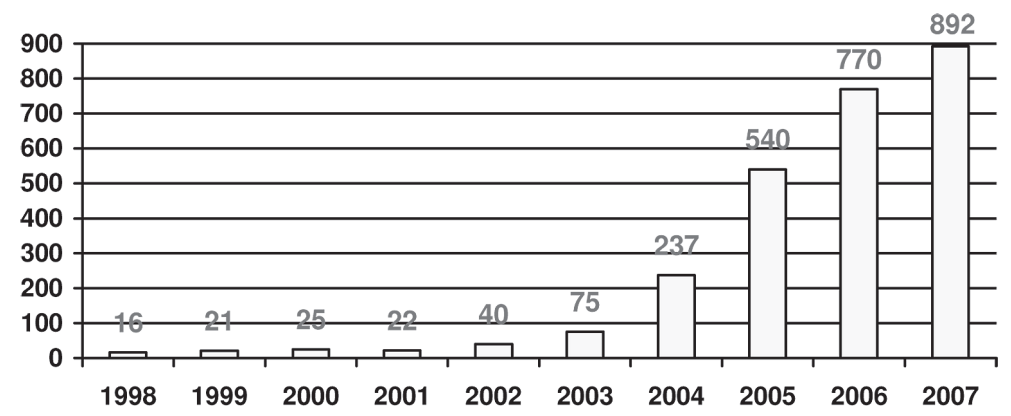

Fig. 6: Overview of the numbers of publications for the years 1998 until 2007 retrieved from the database Medline with the search term "(nanoparticles OR nanomaterials) AND animals" 


\section{Spelling out of the search request}

In accordance with the above mentioned decisions, the following search request was formulated for the years 2004, 2005, 2006, and 2007, respectively, for the European countries Germany, France, United Kingdom, Italy, the Netherlands and Switzerland, respectively: "(nanotechnology OR nanobiotechnology OR nanomedicine OR nanoparticle OR nanomaterial) AND (animal OR mouse OR mice OR rat OR rabbit OR dog OR primate OR fish OR pig) NOT review[pt]."

The search phrase regarding animal species (")(animal OR mouse OR mice OR rat OR rabbit OR dog OR primate OR fish OR pig)") was chosen to cover those species used in research most frequently or entailing specific ethical concern (such as the use of non-human primates and dogs). Due to the inclusion of the general search term "animal", articles presenting research projects using other species, i.e. hamsters, sheep, and horses, were also retrieved. A cross-checking with queries specifically searching for these species did not result in additional retrievals and thus did not reveal the need to add specific search terms for these animal species to the general search phrase.

Reviews were exempt from survey in order to ensure that only articles presenting new scientific results truly gained by the authors of the article in their country of origin were used in the literature survey.

A publication was assigned to a specific country if the main author's affiliation (as determined by postal address) was located in this respective country. (If the postal address of the main author had a different country than his email address, the country of the postal address was taken as decisive.)

\section{Ultrafine particles}

A number of relevant articles covering in vivo or in vitro research on ultrafine particles were already retrieved with the above depicted literature search.
An additional specific search for publications from 20042007 in the mentioned six European countries on ultrafine particles 8 that do not contain the terms "nanotechnology OR nanobiotechnology OR nanomedicine OR nanoparticle OR nanomaterial" resulted in a total of 12 retrievals. Of these, there were 3 publications on studies performing animal experiments and one publication reporting on an in vitro study. These articles are included in the evaluation of the study.

A number of articles covering research on ultrafine particles contained the terms nanoparticle, etc. (e.g. "combustion-derived nanoparticles"), and therefore had been retrieved in the initial literature searches.

The German research strategy for nanotechnology (German Federal Government, 2007) notes that, in principle, "naturally" occurring ultrafine particles and the industrially produced nanoparticles lead to similar biological effects. However, they represent a mixture of substances, with the resulting biochemical consequences, whereas the industrially produced nanoparticles mainly exist as singular substances (pages 25 and 34): "Research results regarding the characteristics and reactions of ultra fine dust (either naturally occurring or resulting due to combustion) can only partially be extrapolated to artificially produced nanomaterials... When occurring "naturally", nanomaterials are very variable in form, composition and size, while "intentionally" produced artificial nanomaterials are manufactured and designed according to desired characteristics... Epidemiological data on the toxicity of heterogeneously composed environmental particulate matter (amongst others, emissions from diesel engines) reveal an increased rate in cardiovascular diseases within the population. Similar effects are also suspected for the nanoscale (ultra fine) fraction of the environmental dusts. The intentionally produced nanomaterials should not be considered as isolated research area. Due to their size, common grounds with the unintentionally occurring (welding fumes,

8 using the search phrase "ultra fine particle" OR "ultra-fine particle" OR "ultrafine particle"

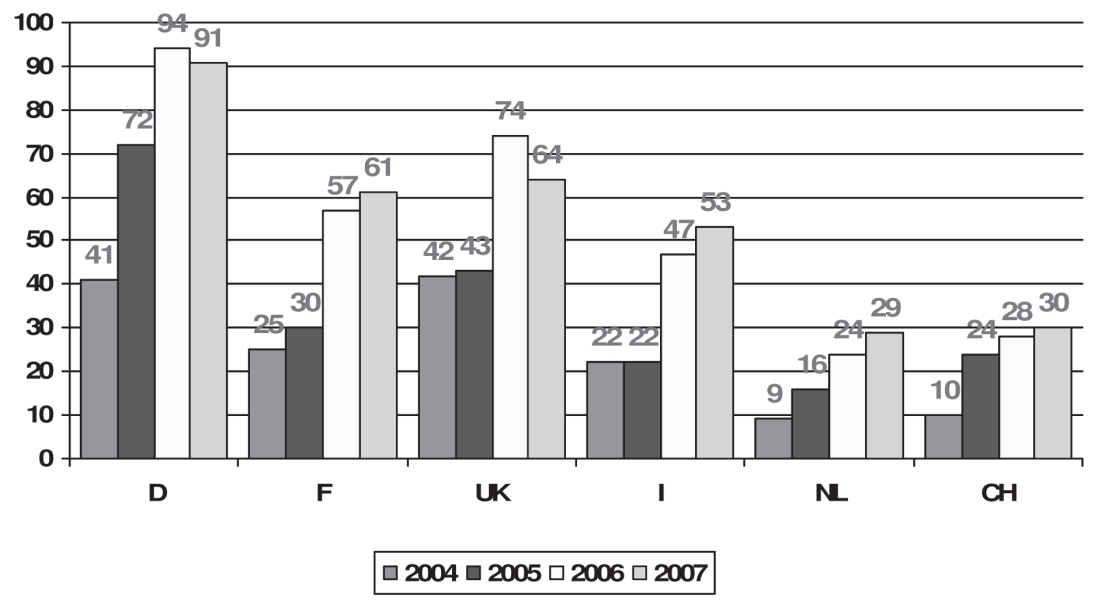

Fig. 7: Numbers of retrieved documents per country per year 
emissions from diesel engines) and natural particles of this size are to be taken into consideration. Likewise, the data of the larger and better investigated fine dusts are of relevance since similarities exist between both particle fractions as regards pulmonary toxicity."9

\section{Performance of literature search}

A total of 1,008 scientific publications were retrieved from Medline with the chosen search request, with the majority of publications originating in Germany (298 publications) and the United Kingdom (223 publications), followed by France (173 publications) and Italy (144 publications) (Tab. 3, Fig. 7).

This amount of documents retrieved was considered to be representative for the purposes of the literature survey.

\section{Assessment of the relevance of the documents retrieved}

In a first step of the assessment, the 1,008 documents retrieved were sorted in accordance to their relevance. Articles were considered to be irrelevant, if the research described in the article either covered the development of nanomaterials or nanoparticles or their physical or chemical characterisation, but no biological evaluations. Such publications were retrieved with the search query either because they mentioned biological material, such as "bovine serum albumin", or because the abstract referred to a possible biomedical application of the nanomaterial or nanotechnology developed, and also because an evaluation of the article revealed that it was indeed a review article even though it had not been marked as such by Medline or because terms of the search query were used figuratively (e.g. "four birds with one stone" 10 ). These documents were not considered any further in the literature survey. Articles were considered to be relevant, if they presented in vivo or in vitro studies with nanomaterials or nanoparticles or in vitro studies or in vivo studies using nanotechnologies.

Of the 1,008 articles retrieved, 685 documents $(68 \%)$ were assessed to be relevant and 323 articles (32\%) to be irrelevant (Tab. 4 and Fig. 8 on page 132).

\footnotetext{
9 original text: „Forschungsergebnisse zum Verhalten und der Wirkung von natürlichem oder durch Verbrennung entstandenem Ultrafeinstaub lassen sich nur partiell auf künstlich erzeugte Nanomaterialien

übertragen... Bei ,natürlicher' Entstehung sind die Nanomaterialien in Form, Zusammensetzung und Größe sehr variabel, während künstlich -

,absichtlich' - erzeugte Nanomaterialien i. d. R. einheitlich nach gewünschten Eigenschaften hergestellt und gestaltet sind... Epidemiologische Daten zur Toxizität der heterogen zusammengesetzten Umweltfeinstäube (u. a. Dieselmotoremissionen) zeigen eine erhöhte Rate an Herz-Kreislauferkrankungen in der Bevölkerung. Ähnliches wird auch für die nanoskalige (ultrafeine) Fraktion der Umweltstäube vermutet. Die beabsichtigt hergestellten Nanomaterialien sollten nicht als isoliertes Forschungsgebiet betrachtet werden. Aufgrund ihrer Größe sind Gemeinsamkeiten mit den unbeabsichtigt entstehenden (Schweißrauche, Dieselmotoremissionen) und natürlichen Partikeln dieser Größe zu berücksichtigen, außerdem sind die Daten der größeren und besser untersuchten Feinstaubpartikel von Bedeutung, da bezüglich der Lungentoxizität Ähnlichkeiten zwischen beiden Partikelfraktionen bestehen." 10 Zhao, L., Yosef, M., Pippel, E. et al. (2006). "Four birds with one stone”: synthesis of nanostructures of ZnTe, Te, ZnAl2O4, and Te/ZnAl2O4 from a single-source precursor. Angew. Chem. Int. Ed. Engl. 45 (47), 8042-8045.
}

\section{Assessment of methodological category of relevant documents}

The 684 relevant documents were sorted according to their methodological category. Methodological categories were "in vivo", "in vivo \& in vitro", and "non-animal" (including documents depicting research conducted in healthy human volunteers of in human patients) in accordance with the method or methods described in the publication.

Of the 684 relevant documents, 164 documents (24\%) depicted research performed either in vivo alone (123 documents

Tab. 3: Total document retrievals from literature search per country per year

\begin{tabular}{|c|c|}
\hline Country and Year & Number of retrievals \\
\hline D 2004 & 41 \\
\hline D 2005 & 72 \\
\hline D 2006 & 94 \\
\hline D 2007 & 91 \\
\hline TOTAL D & 298 \\
\hline F 2004 & 25 \\
\hline F 2005 & 30 \\
\hline F 2006 & 57 \\
\hline F 2007 & 61 \\
\hline TOTAL F & 173 \\
\hline UK 2004 & 42 \\
\hline UK 2005 & 43 \\
\hline UK 2006 & 74 \\
\hline UK 2007 & 64 \\
\hline TOTAL UK & 223 \\
\hline I 2004 & 22 \\
\hline 12005 & 22 \\
\hline 12006 & 47 \\
\hline I 2007 & 53 \\
\hline TOTAL I & 144 \\
\hline NL 2004 & 9 \\
\hline NL 2005 & 16 \\
\hline NL 2006 & 24 \\
\hline NL 2007 & 29 \\
\hline TOTAL NL & 78 \\
\hline Country and Year & Number of retrievals \\
\hline $\mathrm{CH} 2004$ & 10 \\
\hline $\mathrm{CH} 2005$ & 24 \\
\hline $\mathrm{CH} 2006$ & 28 \\
\hline $\mathrm{CH} 2007$ & 30 \\
\hline TOTAL CH & 92 \\
\hline TOTAL 2004 & 149 \\
\hline TOTAL 2005 & 207 \\
\hline TOTAL 2006 & 324 \\
\hline TOTAL 2007 & 328 \\
\hline SUM of Total (D, F, UK) & 1,008 \\
\hline
\end{tabular}


- $18 \%$ of all relevant documents; $7 \%$ of all in vivo documents) or in combination with in vitro methods (41 articles $-6 \%$ of all relevant documents; $25 \%$ of all in vivo documents). 520 articles (76\% of all relevant documents) depicted research performed in non-animal test methods (Tab. 5 and Fig. 9).

\section{Glossary}

Note: partly adapted from:

- Glossary in the Publicly Available Specification "Vocabulary - Nanoparticles" PAS 71:2005 of the British Standards Institution (25 May 2005). http://www.bsi-global.com/en/Standards-and-Publications/ Industry-Sectors/Nanotechnologies/PAS-71/

- http://en.wikipedia.org

Atomic force microscopy, AFM: Technique for imaging surfaces by mechanically scanning their surface contours using a microfabricated probe, in which the deflection of a sharp tip sensing the surface forces, mounted on a soft cantilever, is monitored as the tip is moved across the surface

Confocal fluorescence microscopy, Confocal laser scanning microscopy, Confocal laser scan microscopy, CLSM, LSCM: Microscopy with a confocal (conjugate to the focal point of the lens) pinhole which rejects out of focus fluorescent light for high-resolution optical images producing in-focus images of thick specimens. Images are acquired pointby-point and reconstructed with a computer, allowing three-dimensional reconstructions of topologically complex objects See also: V Prasad, D Semwogerere, ER Weeks (2007). Confocal microscopy of colloids. J Phys: Cond Mat 19, 113102. http:// www.physics.emory.edu/ weeks/lab/papers/prasad06b.pdf http://www.celanphy.science.ru.nl/Bruce $\% 20 \mathrm{web} / \mathrm{scan}-$ ning\%20microscopy.htm

Dendrimer: Synthetic, three-dimensional macromolecule built up from a monomer, with new branches added in a step-bystep fashion until a symmetrical branched structure is created
Tab. 4: Relevant articles in regard to total retrievals (per country per year) for D, F, UK, I, NL, CH

\begin{tabular}{|c|c|c|c|}
\hline & Total & Irrelevant & Relevant \\
\hline D 2004 & 41 & 15 & 26 \\
\hline F 2004 & 25 & 9 & 16 \\
\hline UK 2004 & 42 & 8 & 34 \\
\hline I 2004 & 22 & 6 & 16 \\
\hline NL 2004 & 9 & 5 & 4 \\
\hline $\mathrm{CH} 2004$ & 10 & 5 & 5 \\
\hline TOTAL 2004 & 149 & 48 & 101 \\
\hline D 2005 & 72 & 28 & 44 \\
\hline F 2005 & 30 & 5 & 25 \\
\hline UK 2005 & 43 & 21 & 22 \\
\hline I 2005 & 22 & 8 & 14 \\
\hline NL 2005 & 16 & 9 & 7 \\
\hline CH 2005 & 24 & 12 & 12 \\
\hline TOTAL 2005 & 207 & 83 & 124 \\
\hline D 2006 & 94 & 17 & 77 \\
\hline F 2006 & 57 & 18 & 39 \\
\hline UK 2006 & 74 & 32 & 42 \\
\hline I 2006 & 47 & 13 & 34 \\
\hline NL 2006 & 24 & 10 & 14 \\
\hline CH 2006 & 28 & 7 & 21 \\
\hline TOTAL 2006 & 324 & 97 & 227 \\
\hline D 2007 & 91 & 21 & 70 \\
\hline F 2007 & 61 & 18 & 43 \\
\hline UK 2007 & 64 & 18 & 46 \\
\hline | 2007 & 53 & 12 & 41 \\
\hline NL 2007 & 29 & 15 & 14 \\
\hline CH 2007 & 30 & 12 & 18 \\
\hline TOTAL 2007 & 328 & 96 & 232 \\
\hline SUM of all years & 1008 & 324 & 684 \\
\hline
\end{tabular}

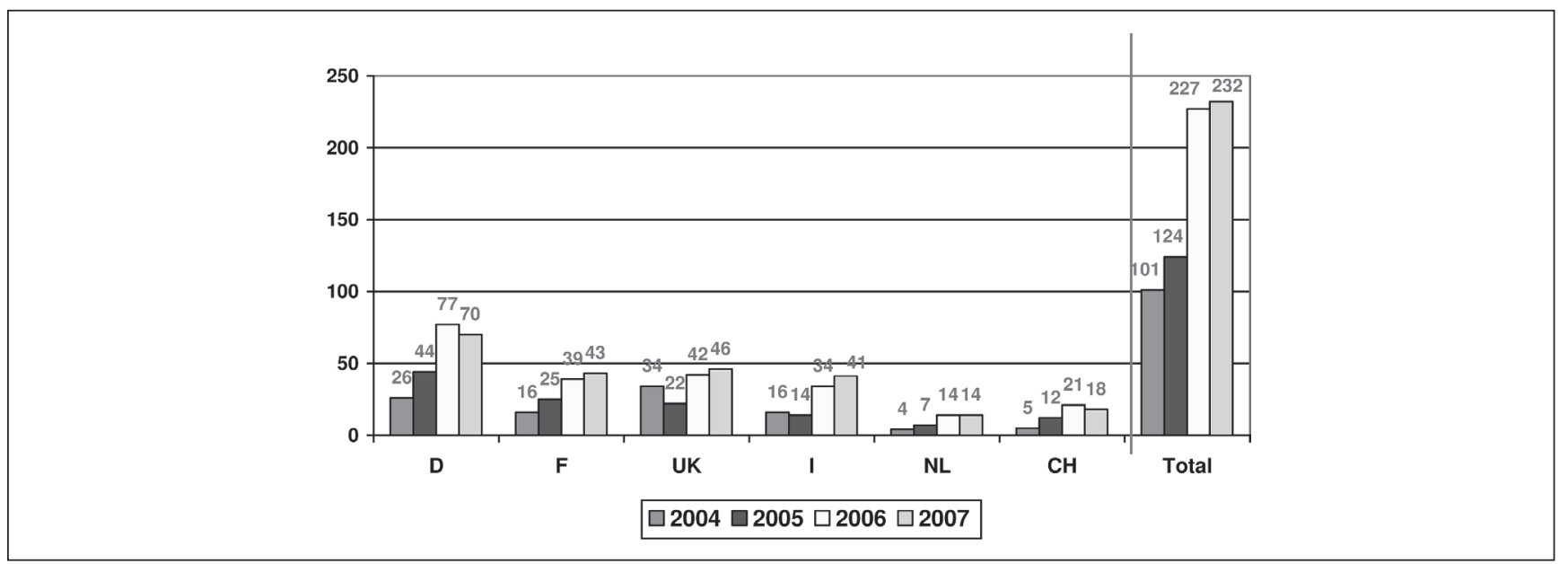

Fig. 8: Relevant articles per country per year (relevant, i.e. describing research performed either with in vivo, in vitro or other non-animal tests, or in tests with human volunteers) 
Tab. 5: Method specification in accordance with year and origin of publication

\begin{tabular}{|c|c|c|c|c|c|}
\hline Country \& Year & In vivo & In vivo \& in vitro & $\begin{array}{l}\text { Sum in vivo + } \\
\text { in vivo \& in vitro }\end{array}$ & Non-animal & TOTAL SUM \\
\hline D 2004 & 4 & 2 & 6 & 20 & 26 \\
\hline F 2004 & 5 & 1 & 6 & 10 & 16 \\
\hline UK 2004 & 2 & 1 & 3 & 31 & 34 \\
\hline 12004 & 1 & 1 & 2 & 14 & 16 \\
\hline NL 2004 & 1 & 0 & 1 & 3 & 4 \\
\hline $\mathrm{CH} 2004$ & 1 & 0 & 1 & 4 & 5 \\
\hline TOTAL 2004 & 14 & 5 & 19 & 82 & 101 \\
\hline D 2005 & 6 & 2 & 8 & 36 & 44 \\
\hline F 2005 & 9 & 4 & 13 & 12 & 25 \\
\hline UK 2005 & 2 & 1 & 3 & 19 & 22 \\
\hline 12005 & 3 & 1 & 4 & 10 & 14 \\
\hline NL 2005 & 2 & 0 & 2 & 5 & 7 \\
\hline $\mathrm{CH} 2005$ & 0 & 3 & 3 & 9 & 12 \\
\hline TOTAL 2005 & 22 & 11 & 33 & 91 & 124 \\
\hline D 2006 & 18 & 2 & 20 & 57 & 77 \\
\hline F 2006 & 9 & 4 & 13 & 26 & 39 \\
\hline UK 2006 & 3 & 1 & 4 & 38 & 42 \\
\hline 12006 & 2 & 1 & 3 & 31 & 34 \\
\hline NL 2006 & 3 & 1 & 4 & 10 & 14 \\
\hline $\mathrm{CH} 2006$ & 5 & 3 & 8 & 13 & 21 \\
\hline TOTAL 2006 & 40 & 12 & 52 & 175 & 227 \\
\hline D 2007 & 16 & 3 & 19 & 51 & 70 \\
\hline F 2007 & 11 & 5 & 16 & 27 & 43 \\
\hline UK 2007 & 5 & 2 & 7 & 39 & 46 \\
\hline I 2007 & 4 & 1 & 5 & 36 & 41 \\
\hline NL 2007 & 3 & 1 & 4 & 10 & 14 \\
\hline $\mathrm{CH} 2007$ & 8 & 1 & 9 & 9 & 18 \\
\hline TOTAL 2007 & 47 & 13 & 60 & 172 & 232 \\
\hline TOTAL SUM, all years & 123 & 41 & 164 & 520 & 684 \\
\hline TOTAL, PERCENTAGE, & 18 & 6 & 24 & 76 & 100 \\
\hline IN VIVO PERCENTAGE & 75 & 25 & 100 & - & - \\
\hline
\end{tabular}

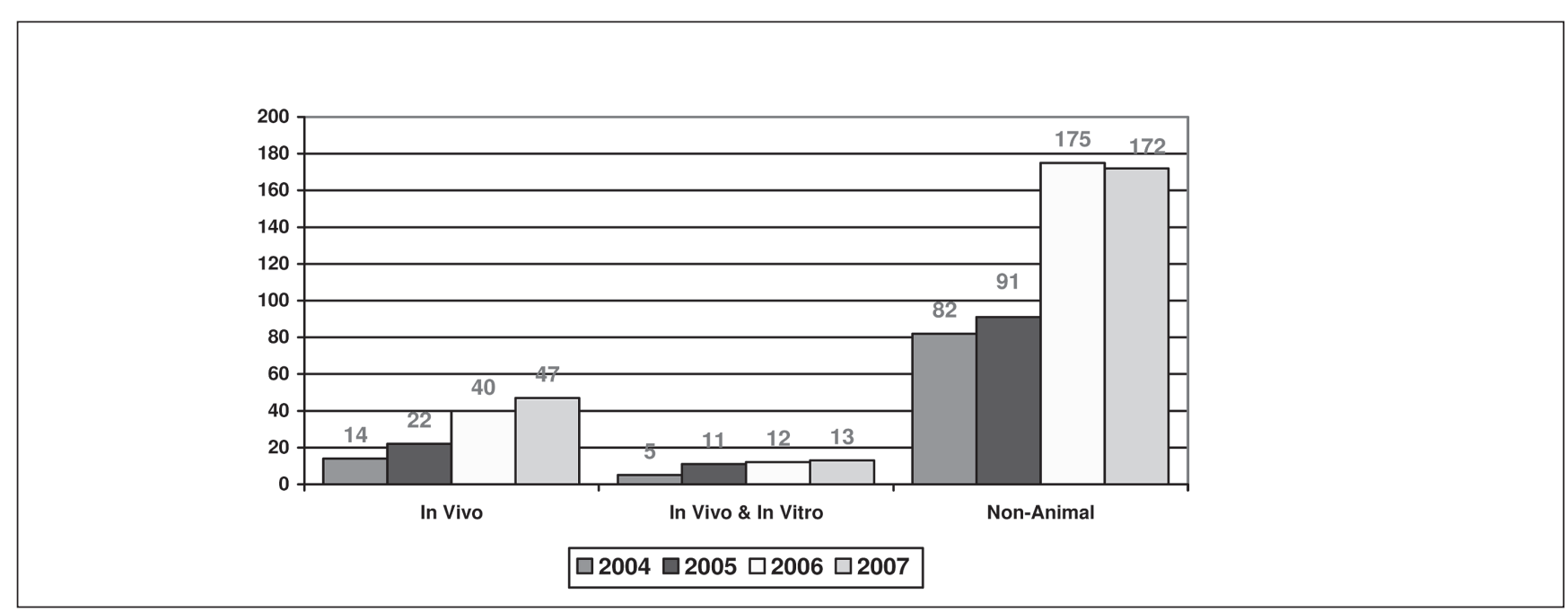

Fig. 9: Method specification in accordance with year of publication 
Dendriplex: DNA-dendrimer complex

Flow cytometry: A technique for counting, examining, and sorting microscopic particles suspended in a stream of fluid Langmuir-Blodgett lithography: A method to fabricate nanotopographically patterened surfaces.

Microfluidics: The science of building miniaturized devices with chambers and tunnels with dimensions well below $1 \mathrm{~mm}$ in which microliters or even nanoliters of fluids flow and in which cells can be cultured

Microplate fluorescence quantification method: Microplate fluorescence assay for DNA quantification

Nanocapsule: A submicroscopic colloidal drug carrier system composed of an oily or an aqueous core surrounded by a thin polymer membrane

Couvreur, P., Barratt, G., Fattal, E. et al. (2002). Nanocapsule technology: a review. Crit. Rev. Ther. Drug Carrier Syst. 19(2), 99-134.

Nanocomposite: Material produced by introducing nanoparticles into a macroscopic material, thereby enhancing its properties Nanomaterial: Material with one or more external dimensions, or an internal structure, on the nanoscale, which could exhibit novel characteristics compared to the same material without nanoscale features

Nanomedicine: Nanotechnology in the health care area Nanoparticle: Particle with one or more dimensions at the nanoscale

Nanopipette: Pipette on the nanometer scale spouting or sucking ultrasmall volumes of fluid

Nanoscale, nanosize: Having one or more dimensions of the order of $100 \mathrm{~nm}$ or less

Nanoscience: Study of (biological) objects ranging from hundreds to tens of nanometers in size

Nanostructure: Structure at the nanoscale

Nanotechnology: Investigations and technological developments on the scale of 1-100 nm, using manufactured particles and material with one or more nanoscale dimensions or structures which exhibit novel (physical) characteristics compared to the same bulk chemical without nanoscale features

Optical tweezers: Optical Tweezers use light to manipulate microscopic objects as small as a single atom.

http://www.stanford.edu/group/blocklab/Optical\%20Tweezers\%20Introduction.htm
Optical stretcher: A laser tool to micromanipulate cells Polyalkylcyanoacrylate and Polyisohexylcyanoacrylate (PIHCA): Synthetic biodegradable polymers

Poly(ethyleneglycol), PEG, PEG-ylated: Commercially available polymer of ethylene oxide. When a PEG is coupled to another molecule, this is referred to as "PEG-ylated".

Polysorbate: Emulsifier used in pharmaceuticals, cosmetics and food preparations

Quantum dot Nanoscale: particle that exhibits size-dependent electronic and optical properties due to quantum confinement

Secondary ion mass spectrometry (SIMS): Technique of analyzing the composition of solid surfaces by scanning it with a focused primary ion beam and collecting and analyzing ejected secondary ions

Spatially modulated illumination microscopy, SMI microscopy, spatially modulated illumination fluorescence microscopy: Microscopy which uses non-uniform excitation for improved resolution and can measure the sizes of objects with diameters ranging between 10-200nm

See: Martin, S., Failla, A. V., Spöri, U. et al. (2004). Measuring the size of biological nanostructures with spatially modulated illumination microscopy. Mol. Biol. Cell 10, 1091. http://www. molbiolcell.org/cgi/content/abstract/E04-01-0045v1?ck=nck

Superparamagnetic nanoparticles, superparamagnetic iron oxide (SPIO; SPION): Superparamagnetism: the phenomenon that magnetic crystallites of 1-10nm diameter exhibit paramagnetic behaviour. When an external magnetic field is applied, the magnetic moment of the entire crystallite aligns with the magnetic field.

See: Vejpravova, J. P. and Sechovsky, V. (2005). Superparamagnetism of co-ferrite nanoparticles. WDS'05 proceedings of contributed papers, part III, 518-523. http://www.mff.cuni.cz/veda/ konference/wds/contents/pdf05/WDS05_090_f3_Vejpravova.pdf SPIOs are used e.g. as MRI contrast agents

Time-of-flight secondary ion mass spectrometry (ToF-SIMS): Secondary ion mass spectrometry* in which the ions are accelerated by an electric field of known strength. The time it takes for the particle to reach a detector at a known distance is measured. 